2014

IMPLEMENTATION OF PHOTOGRAMMETRY TO IMPROVE PROACTIVE ASSESSMENT OF RETAINING WALLS ALONG TRANSPORTATION CORRIDORS

Daniel J. Cerminaro

Michigan Technological University

Follow this and additional works at: https://digitalcommons.mtu.edu/etds

Part of the Remote Sensing Commons

Copyright 2014 Daniel J. Cerminaro

Recommended Citation

Cerminaro, Daniel J., "IMPLEMENTATION OF PHOTOGRAMMETRY TO IMPROVE PROACTIVE ASSESSMENT OF RETAINING WALLS ALONG TRANSPORTATION CORRIDORS", Master's Thesis, Michigan Technological University, 2014.

https://doi.org/10.37099/mtu.dc.etds/869

Follow this and additional works at: https://digitalcommons.mtu.edu/etds

Part of the Remote Sensing Commons 


\title{
IMPLEMENTATION OF PHOTOGRAMMETRY TO IMPROVE PROACTIVE ASSESSMENT OF RETAINING WALLS ALONG TRANSPORTATION CORRIDORS
}

By

Daniel J Cerminaro

\begin{abstract}
A THESIS
Submitted in partial fulfillment of the requirements for the degree of MASTER OF SCIENCE

In Civil Engineering
\end{abstract}

MICHIGAN TECHNOLOGICAL UNIVERSITY

2014

(C) 2014 Daniel J Cerminaro 
This thesis has been approved in partial fulfillment of the requirements for the Degree of MASTER OF SCIENCE in Civil Engineering.

\title{
Department of Civil and Environmental Engineering
}

\section{Thesis Advisor: Thomas Oommen}

Committee Member: Stanley Vitton

Committee Member: $\quad$ Rüdiger Escobar Wolf

\author{
Department Chair: David Hand
}




\section{TABLE OF CONTENTS}

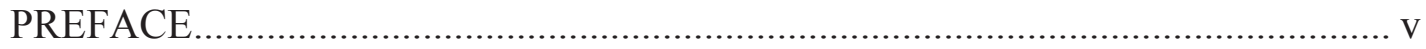

ACKNOWLEDGEMENTS .......................................................................... vi

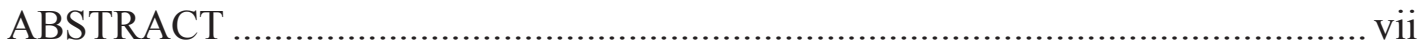

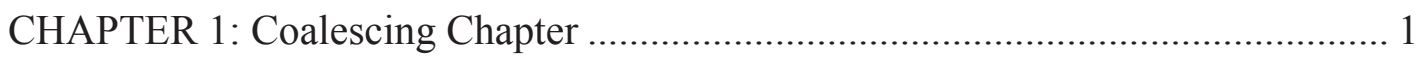

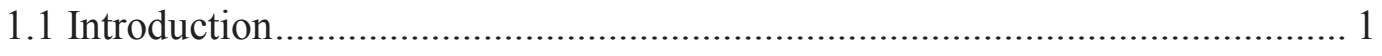

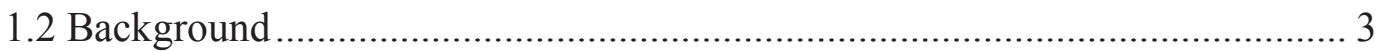

1.2.1 Retaining Walls Condition Assessment .............................................. 3

1.2.2 Using Photogrammetry for Condition Assessment................................ 4

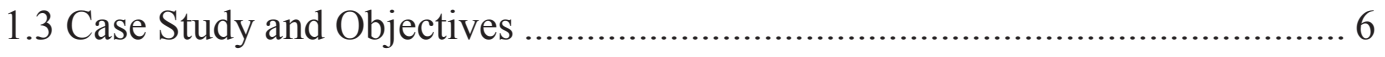

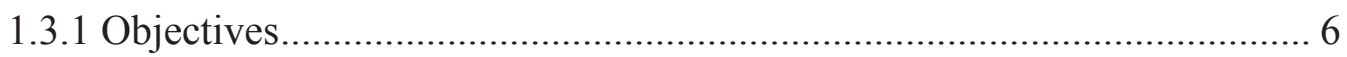

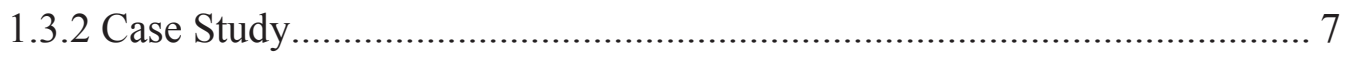

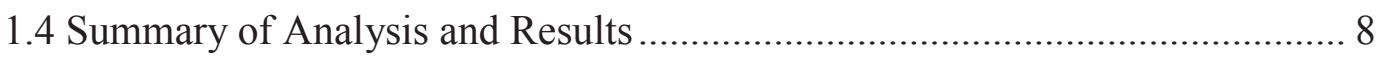

1.4.1 Laboratory Scale Model ................................................................. 9

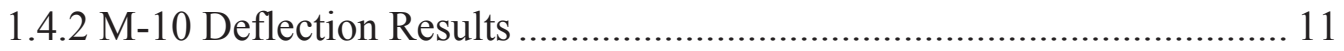

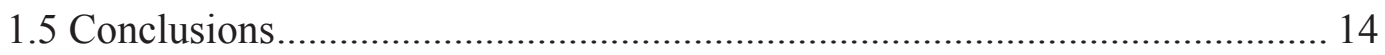

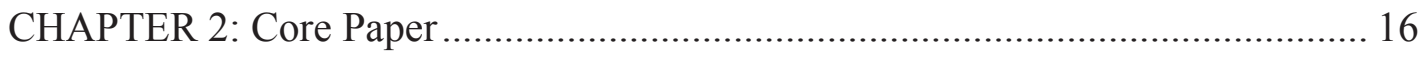

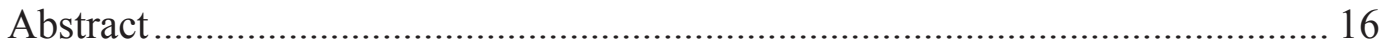

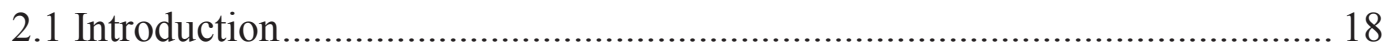

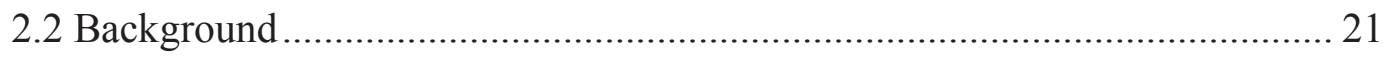


2.2.1 Current Methods for Retaining Walls Condition Assessment

2.2.2 Case Study: M-10 Highway Retaining Walls ..................................... 22

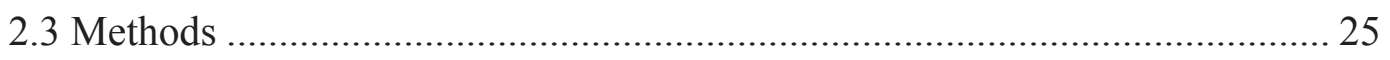

2.3.1 Principles of Photogrammetry ....................................................... 26

2.3.2 Laboratory and Field Work - Data Collection..................................... 28

3.2.3 3D Modelling and Point Cloud Creation .......................................... 33

2.3.4 Multi-temporal Model Registration and Point Cloud Comparison.......... 34

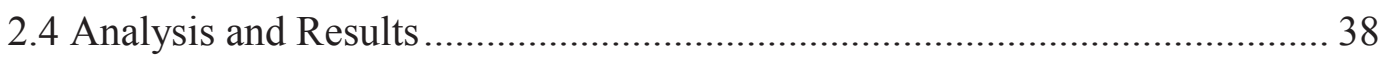

2.4.1 Laboratory Scale Model Deflection Measurements.............................. 38

2.4.2 M-10 Deflection Measurements......................................................... 44

2.5 Conclusions and Future Work .......................................................... 50

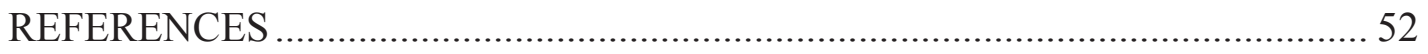

APPENDIX A: Plots of the laboratory small scale model point cloud accuracy..... 56 APPENDIX B: Value Differences from change detection from March and June

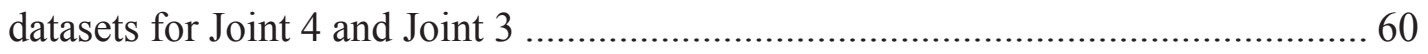




\section{PREFACE}

The work presented in this thesis is original and was completed by myself in collaboration with the co-authors of the core paper "Implementation of Photogrammetry to Improve Proactive Assessment of Retaining Walls along Transportation Corridors". The majority of the laboratory and field work analysis and

processing was completed by Rudiger Escobar Wolf and myself. Also, the core paper was written by myself with the guidance of my committee members. 


\section{ACKNOWLEDGEMENTS}

This research was fully supported by the National Science Foundation under the Graduate Research Fellowship Program (GRFP) Grant No. DGE-1051031, U.S. Department of Transportation Research and Innovative Technology Administration (USDOT- OSTR-R) under cooperative agreement RITARS-14-H-MTU, and the Michigan Space Grant Consortium. The views, opinions, findings, and conclusions reflected in this thesis are the responsibility of the authors only and do not represent the official policy or position of the USDOT-OST-R, or any state or other entity.

The work presented in this thesis wouldn't be possible without the guidance and input from my advisor Dr. Thomas Oommen and committee members Dr. Rudiger Escobar Wolf and Dr. Stanley Vitton who I would like to thank for their support.

I would also like to thank Richard Endres, James Siler, and Peter Jansson from MDOT for their help in planning and coordinating the field data collection trips.

To my friend Daniel Lidman for his faithful help during field work, and to Rick Dobson for his support.

Finally, I would like to express my gratitude to my wife Staci Cerminaro and daughter Avery Cerminaro for their unconditional and faithful support throughout my academic career. 


\begin{abstract}
Retaining walls are important assets in the transportation infrastructure and assessing their condition is important to prolong their performance and ultimately their design life. Retaining walls are often overlooked and only a few transportation asset management programs consider them in their inventory. Because these programs are few, the techniques used to assess their condition focus on a qualitative assessment as opposed to a quantitative approach. The work presented in this thesis focuses on using photogrammetry to quantitatively assess the condition of retaining walls. Multitemporal photogrammetry is used to develop 3D models of the retaining walls, from which offset displacements are measured to assess their condition. This study presents a case study from a site along M-10 highway in Detroit, MI were several sections of retaining walls have experienced horizontal displacement towards the highway. The results are validated by comparing with field observations and measurements. The limitations of photogrammetry were also studied by using a small scale model in the laboratory. The analysis found that the accuracy of the offset displacement measurements is dependent on the distance between the retaining wall and the sensor, location of the reference points in 3D space, and the focal length of the lenses used by the camera. These parameters were not ideal for the case study at the M-10 highway site, but the results provided consistent trends in the movement of the retaining wall that couldn't be validated from offset measurements. The findings of this study confirm that photogrammetry shows promise in generating 3D models to provide a quantitative condition assessment for retaining walls within its limitations.
\end{abstract}




\section{CHAPTER 1: Coalescing Chapter}

\subsection{Introduction}

Geotechnical assets such as retaining walls are indispensable components for healthy transportation infrastructure. The primary purpose for retaining walls along transportation corridors is to retain earthen materials (Bernhardt et al. 2003). From a roadway performance perspective, a retaining wall is expected to adequately retain earthen materials to prevent blockages, intrusions, and damages to any roadway structures and failure to do so can be considered failure (DeMarco et al. 2009). Failure in a retaining wall can also be described in terms of its deviations from its original design and purpose so it does not necessarily have to collapse in order to be considered a failure (Wendland 2011).

According to the American Association of State Highway and Transportations Officials' (AASHTO) Transportation Asset Management Guide over the past decade there has been a growing awareness that the current methods of transportation infrastructure management are not adequate to meet the demands of the public and therefore need improvement (AASHTO 2013). AASHTO defines transportation asset management as “...a strategic and systematic process of operating, maintaining, upgrading, and expanding physical assets effectively through-out their life cycle."(AASHTO 2013). Retaining walls are important physical assets in transportation corridors but are often not included and therefore only few asset management programs do include them in their inventory (Anderson et al. 2008). 
A retaining wall asset management program consists of three main steps (Anderson et al. 2008). The first step is to conduct an inventory of the retaining wall that defines the type of wall, physical properties, and location. The second step is to assess the condition of the retaining wall. This step is divided into a regional and local scale assessment. A regional assessment would conduct an evaluation of a large network of geotechnical assets (Oommen et al. 2013). The local scale assessment, also known as performance monitoring, focuses on defining the current state of the wall based on its needs (Schaefer et al. 2013). The last step is to take the information from the assessment and use to predict change in the retaining wall conditions through time (Anderson and Rivers 2013).

Current methods for assessing the condition of the retaining wall include traditional field inspections and surveys which in most cases provide a qualitative condition description. (Anderson et al. 2008). The objective of this study is to assess the applicability of photogrammetry to provide a quantitative assessment of the condition of a retaining wall. A case study is presented from a series of retaining wall along M10 highway in Detroit, Michigan. The case study focuses on quantifying the deflection of a section of retaining wall by obtaining measurements from 3D models created from $2 \mathrm{D}$ photographs. To identify the best practices for field data collection and to validate the accuracy of the field results a small scale model was built in the laboratory. The development and validation of results from the laboratory study are also presented in this paper. 


\subsection{Background}

\subsubsection{Retaining Walls Condition Assessment}

One of the primary reasons to assess the condition of a retaining wall is to have the ability to predict its future behavior. Ultimately these predictions would help to reduce the life-cycle costs associated with construction and maintenance of the retaining walls along indicated transportation corridors (Bernhardt et al. 2003). Within the last decade a survey indicated that very few public agencies have experience with retaining wall condition assessment (Anderson et al. 2008). One of the main reasons for this is that most agencies who have started asset management programs are still trying to figure out how to properly implement the process. The Federal Highway Administration (FHWA) who works conjunctly with the National Park Service (NPS) along with Alaska DOT and Colorado DOT have the most established and substantial retaining walls asset management programs in the country (Minnesota DOT 2013). The program developed by the FHWA along with the NPS is identified as the Wall Inventory Program (WIP). This program focuses on conducting inventories, condition assessment, and defining and quantifying the cost of structure maintenance, repair, or replacement of all the retaining walls within the national park systems. Since the program started in $2005,3,500$ retaining walls have been included to the WIP database (DeMarco et al. 2009). The condition assessment in the WIP is done by field inspections where the inspector describes the condition of the wall by assigning a numerical rating to individual wall elements. These ratings are weighed and a final 
condition rating is assigned to the wall (CFLHD 2010). A detailed discussion concerning this rating system can be found in the "Retaining Wall Inventory and Condition Assessment Program (WIP) Procedure Manual" by the NPS. This condition assessment is mostly based on a qualitative rating. Figure 1-1 shows a form used by the WIP field inspectors to record the assessment of a retaining wall. The rating is based on the characteristics of the retaining wall and its adjacent section's.

\begin{tabular}{|c|c|c|c|}
\hline Category & $\begin{array}{c}\text { Technical } \\
\text { Significance }\end{array}$ & $\begin{array}{c}\text { Condition } \\
\text { Score }\end{array}$ & $\begin{array}{c}\text { Category } \\
\text { Rating }\end{array}$ \\
\hline Maximum Value & 10 & 10 & \\
\hline $\begin{array}{c}\text { Performance } \\
\text { Remaining Age } \\
\text { Ductility }\end{array}$ & $\begin{array}{l}6 \\
4 \\
2 \\
\end{array}$ & $\begin{array}{c}10 \\
10 \\
5 \\
\end{array}$ & $\begin{array}{c}60 \\
4 \\
10 \\
\end{array}$ \\
\hline $\begin{array}{l}\text { Wall Element } 1 \\
\text { Wall Element } 2 \\
\text { Wall Element } 3\end{array}$ & $\begin{array}{l}7 \\
4 \\
2\end{array}$ & $\begin{array}{l}4 \\
4 \\
4\end{array}$ & $\begin{array}{c}28 \\
16 \\
8 \\
\end{array}$ \\
\hline $\begin{array}{l}\text { Adjacent Element } 1 \\
\text { Adjacent Element } 2 \\
\text { Adjacent Element } 3\end{array}$ & $\begin{array}{l}4 \\
2 \\
1\end{array}$ & $\begin{array}{l}8 \\
4 \\
2\end{array}$ & $\begin{array}{l}8 \\
4 \\
2\end{array}$ \\
\hline & & Total: & 176 \\
\hline & & $\begin{array}{r}\text { Maximum } \\
\text { Possible Score: }\end{array}$ & 320 \\
\hline & & Rating: & 55 \\
\hline
\end{tabular}

Figure 1-1 WIP retaining wall condition rating data input form. Modified from Anderson et al. (2008).

\subsubsection{Using Photogrammetry for Condition Assessment}

Photogrammetry is a technology that provides the ability to obtain quantitative measurements from 3D models created from 2D images and has been used for assessing the condition of transportation assets (Wolf and Dewitt 2000). In 1977 the 
Washington State Highway Department collaborated with the FHWA to fund a research project that used photogrammetry to monitor highway structures (Veress et al. 1977). Although optical sensor technology was still in early development stages, the research project was able to develop and implement a simple method to provide an accurate georeferenced 3D model of a gabion wall (Veress et al. 1977). Recent advancements in optical cameras and 3D modelling software, however, have allowed photogrammetry to become a powerful tool for 3D modelling (Remondino and El Hakim 2006; Westoby et al. 2012). Given these advancements, photogrammetric modelling is currently being used in a wide range of applications such as monitoring river bed topography, gully erosion, rock slope stability, and glacier surface change (Westoby et al. 2012). Photogrammetry has also shown to be a reliable technology to accurately measure vertical deflections and camber in bridges (Jauregui et al. 2003).

Photogrammetric data can be collected from satellite, aerial, and terrestrial platforms. Aerial and satellite are considered to be long-range photogrammetric data, while terrestrial photogrammetry is considered close-range (Matthews 2008). Some of the field data collection advantages of collecting data from any of these platforms is that large areas can be covered in a short amount of time, and the equipment is small, portable, and relatively inexpensive. The most important advantage is that photogrammetry provides the ability to objectively quantify the characteristics of an asset such as a retaining wall for an unbiased condition assessment. 


\subsection{Case Study and Objectives}

\subsubsection{Objectives}

The objective of this study is to verify the applicability of photogrammetry to assess the condition of retaining walls along highway infrastructure corridors. This objective was achieved by conducting the following tasks:

(i) Collaborate with a transportation agency to find an appropriate site where a retaining wall had experienced significant and measurable deflection.

(ii) Construct a laboatory scale model of the retaining wall that can simulate deflection under controlled conditions.

(iii) Use the laboratory scale model to develop and apply the most efficient photogrammetric data collection procedures in the field.

(iv) Understand and develop the most appropriate and efficient data processing techniques to capture deflection using photogrammetry.

(v) Make the results from this study available for further refinement and research continuance.

The results and findings from this study are presented in Chapter 2, which is a technical paper prepared for submission to the Journal of Computing in Civil Engineering. 


\subsubsection{Case Study}

The study site is located near Meyers Road on the M-10 highway in Detroit, Michigan. At this location M-10 highway is a depressed highway with retaining walls on each side. The highway has three lanes Southbound and three lanes Northbound with service drives running parallel to it. For practical purposes the site is referred-to as the "Meyers Site" in this study. Figure 1-2 shows the Meyers site on the M-10

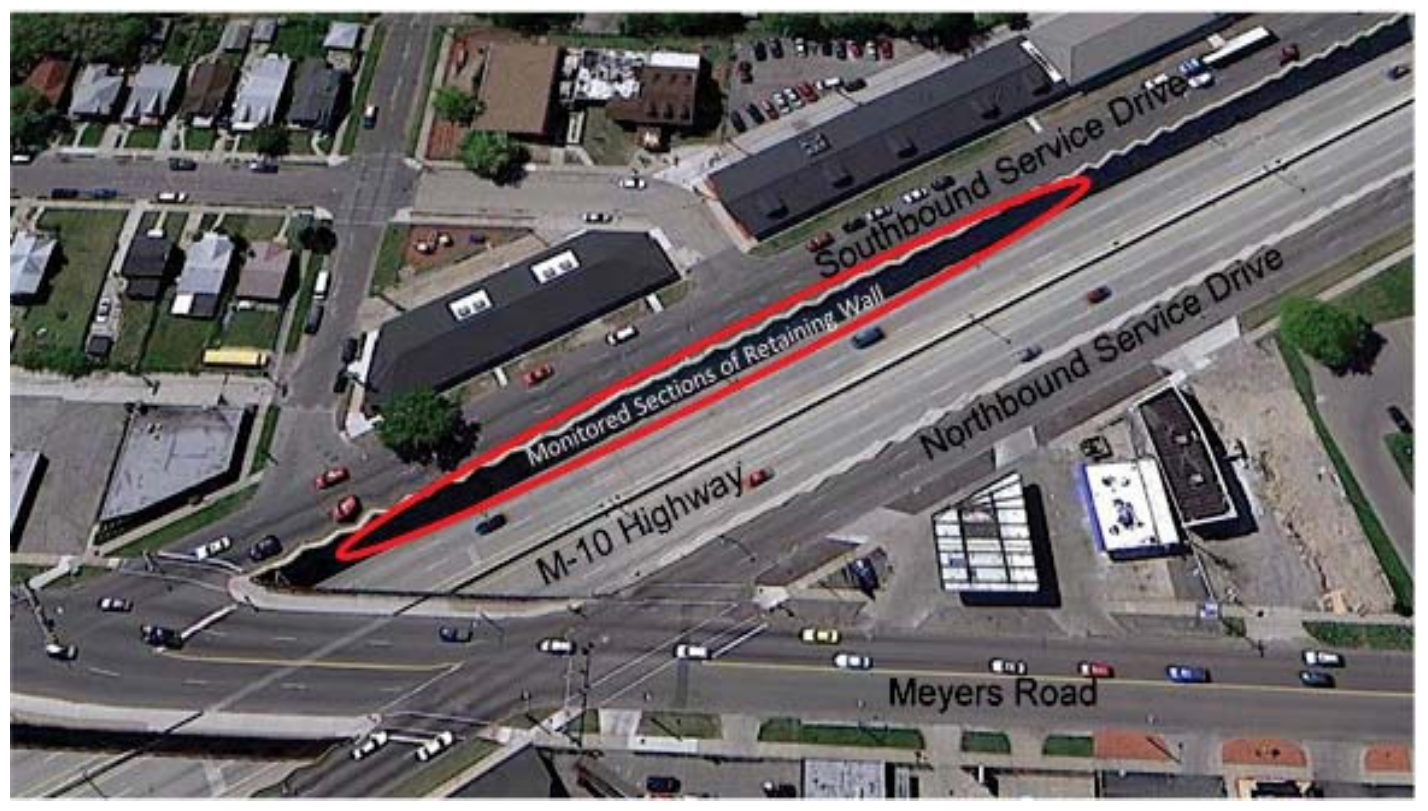

Figure 1-2 Location of Meyers site on M-10 highway North West of downtown Detroit. Modified from Google Earth (2014).

highway.

Over the last few years the Michigan Department of Transportation (MDOT) noticed that some sections of retaining wall at several locations along the highway had experienced significant movement. During 2013 one of these sections was found to 
have tilted $3.15 \mathrm{in}(8 \mathrm{~cm})$ towards the highway, which led to its failure and subsequently had to be removed and replaced (Jansson 2013). After this failure MDOT started monitoring several sections of retaining wall along the highway that indicated movement. During the spring of 2014 it was found that several sections of wall had experienced significant movement near the location where Meyers Road overpasses the M-10 Highway. MDOT monitored the retaining wall by measuring offset deflection between two adjacent sections of retaining wall's expansion joints. These measurements were obtained by using a measuring tape and tilt monitors. The measurements show that between May, 2013 and August, 2014 the section with the most movement deflected $0.75 \mathrm{in}(1.90 \mathrm{~cm})$ at the top of the wall tilting towards the M-10 Highway. The total deflection including movement before the site was monitored was determined to be 3 in $(7.62 \mathrm{~cm})$ at the top of the wall, again, where the movement is towards M-10 highway. It is important to note that there was no offset at the bottom of the wall, so the movement can be described in terms of tilt.

\subsection{Summary of Analysis and Results}

This work focused on obtaining deflection measurements from 3D models created from photogrammetric data collected between March 2014 and August 2014 from the Meyers site. The process to obtain the deflection measurements consists of four main steps. The first step involves creating reference points on the retaining walls which were used to establish a scale and georeferencing for the 3D models. The second step consists of collecting photographs from the retaining wall using an optical camera. In 
the third step the 3D models are created using 3D modelling software and the $2 \mathrm{D}$ photographs. The software uses the photographs and reference points to extract the location of each point on the surface of the wall in 3D space, it then uses this information to create a 3D model. The last step entails comparing two 3D models from two points in time and analyzing the changes to obtain deflection measurements.

\subsubsection{Laboratory Scale Model}

A scaled model was constructed in a laboratory setting to simulate two sections of retaining wall with an expansion joint in the middle. The model provided the ability to simulate the deflection at the Meyers site under a controlled environment. The model was used to determine the best data collection methods to use in the field. The model is composed of two identical sections that when put together have a size of $8 \mathrm{ft}$ high by $8 \mathrm{ft}$ wide. Each section is able to simulate deflection at the top of the wall by rotating about two hinges fixed at the bottom. Once the model was set up reference points were marked on fixed locations on the model. Figure 1-3 shows the reference points that were used to generate a local coordinate system that would define the scale and were also used for georeferencing the 3D models. 


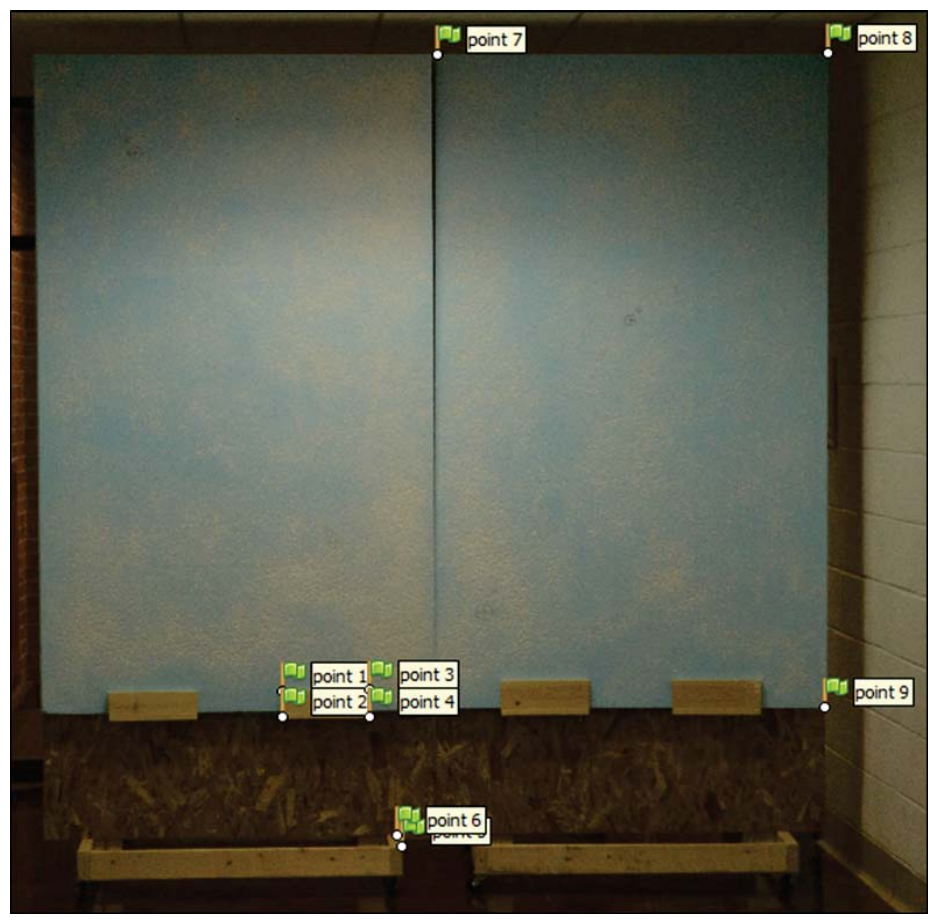

Figure 1-3 Laboratory scale model with the reference points used for registration.

The small scale model was also used to find the accuracy of the offset measurements from the 3D models created from data collected at various distances. To find the accuracy at a specific distance, two sets of data were collected from the small scale model at various distances ranging from $20 \mathrm{ft}$ to $100 \mathrm{ft}$. The first set of data at each distance simulated the small scale model with no deflection and the second set of data at each distance was collected from the model with one panel (section of retaining wall) having a deflection of 3.25 in relative to the adjacent section. The distances were recorded from the surface of the small scale model wall to the location of the camera. For each distance the deflection was calculated from the 3D models and then compared to the true deflection of $3.25 \mathrm{in}$. The comparison shows that the accuracy of 
the measurements from the $3 \mathrm{D}$ models decreases as the distance between the small scale model and the camera increase. The results show that the deflection measurements can be accurate when the data is captured within a distance of $40 \mathrm{ft}$. Any measurements made from 3D models created from data collected at a distance greater than $50 \mathrm{ft}$ are significantly less accurate. It is important to note that these results show the total accuracy of the software processing combined with the accuracy of the specific camera and focal length used in this study. The theoretical accuracy of the camera relative to the focal length suggests that an increase in the focal length would increase the accuracy of the 3D model offset measurements at any specific distance. The results from this study are presented in Chapter 2.

\subsubsection{M-10 Deflection Results}

The scale model proved to be a significant asset to determine the best field data collection procedures. The scale model accuracy versus distance study was also instrumental to understand and validate the accuracy of the offset measurements obtained from the Meyers site 3D models. It is important to acknowledge that the accuracy study was done after the field data was collected. The results from this study showed that the data collection procedures used in the field can be refined to get more accurate results.

Three field datasets were used for this study. The first one was collected on March 11,2014 , the second dataset was collected on June 23, 2014 and the last dataset was 
collected on August 15, 2014. During the field trips the focus was to collect data from the retaining wall that experienced the most movement. One of the walls that MDOT was monitoring moved 0.22in $(0.55 \mathrm{~cm})$ towards M-10 highway from March 13, 2014 to August 15, 2014. Figure 1-4 shows the section of wall which is between expansion joints 3 and 4.The movement was measured in terms of offset relative to the adjacent walls at the expansion joints using a measuring tape and was confirmed by tilt-meter monitoring.

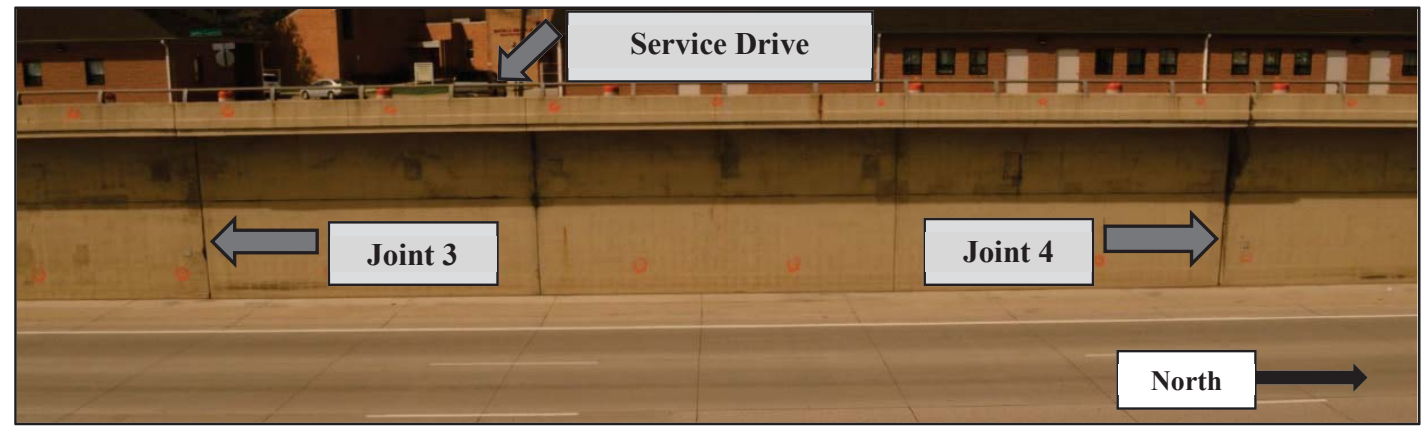

Figure 1-4 Section of retaining wall which experienced the most movement at the Meyers site on M-10 highway between Joint 3 and Joint 4.

At the Meyers site the data was collected from the service drive (Northbound Service Drive) opposite to the retaining walls being monitored (See Figure 1-2). The distance between the surface of the wall and the camera was approximately $100 \mathrm{ft}$ for each data set. After the 3D model comparison the resulting offset measurements indicate that between March and August the section of retaining wall, which moved the most, moved 0.24 in $(0.60 \mathrm{~cm})$ away from M-10 highway. These offset measurements are not very reliable, since the actual offset measurements are smaller than the margin of 
error for a data collection at the distance of 100ft. This is issue is discussed with further detail in Chapter 2.

Offset measurements were acquired from 3D model comparisons for March - June and March - August data sets. Although the deflection results are not reliable the 3D model comparisons show a consistent trend in horizontal movement on both sides of Joint 4. The movement appears to indicate that both sections on either side of Joint 4 are moving simultaneously toward M-10 highway while also moving relative to one another. It also indicates horizontal movement at the top and bottom of the wall.

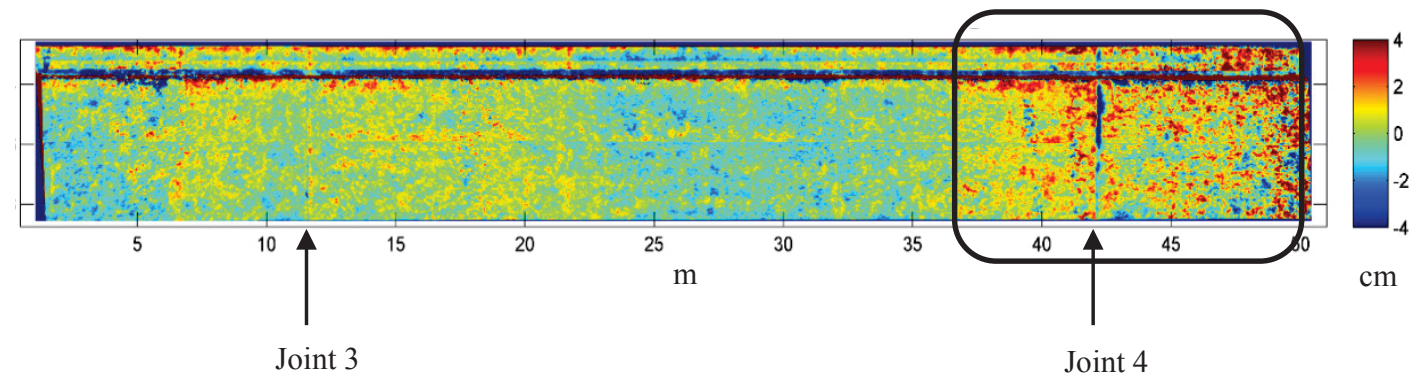

Figure 1-5 Value differences from comparison of March and August's 3D models. Most horizontal movement towards M-10 is highlighted in the area inside the box at Joint 4.

Figure 1-5 shows the results from the comparison of the March - August datasets and it also shows the area where both sections of retaining wall on either side of Joint 4 seem to be moving towards M-10 highway. This movement is strongly evident in the results presented in Figure 1-5, but since it was not expected it could not be validated from field measurements. The field measurements focused on relative offsets using 
the adjacent walls as a reference. The movement of the walls shown in Figure 1-5 is in terms of absolute movement. Future work should look into field techniques to validate this movement.

\subsection{Conclusions}

Retaining walls are an important part of the nation's highway infrastructure, so it is important to monitor their performance to avoid hazardous failures. Current methods to assess the condition of retaining walls rely mostly on methods that provide a qualitative description of the asset which can be subjective to the interpretation of the field inspectors. This study introduces photogrammetry technology which can be used to provide unbiased quantitative condition assessment of a retaining wall within its limitations. The results from the laboratory case study presented in this work show that the deflection from a section of retaining wall relative to the adjacent section can be quantified by comparing two 3D models from data collected at two different times. The results show that the accuracy of the measurements depend on the distance between the camera and the retaining wall as well as the focal length used for data collection. The final results from the 3D model comparison from the Meyers site, however, did not provide reliable deflection measurements. The unreliability of the results is due the actual deflection was not within the accuracy range of the models which were collected at a distance of $100 \mathrm{ft}$. Although the deflection measurements are not accurate for the Meyers site, the results show strong evidence of horizontal displacement towards M-10 highway on both sections of retaining on either side of 
Joint 4. This movement was not able to be validated with this study's field measurements, so future work should focus on developing field techniques that can be used to verify this movement.

Future work should also look into how the accuracy of the measurements from the 3D models can be improved at distances greater than $50 \mathrm{ft}$. Other work should include performing this same process for data collected from mobile and perhaps aerial platforms. And finally, the results from this study should be compared with those from other remote sensing technologies such as light detecting and ranging (LIDAR) and interferometric synthetic aperture radar (InSAR) when this data is available. 


\title{
CHAPTER 2: Core Paper*
}

\section{Implementation of Photogrammetry to Improve Proactive Assessment of Retaining Walls along Transportation Corridors}

Daniel J Cerminaro ${ }^{1}$, Rudiger Escobar-Wolf ${ }^{2}$, Thomas Oommen ${ }^{2}$, and Stan Vitton ${ }^{1}$

${ }^{1}$ Department of Civil and Environmental Engineering, Michigan Technological University, Houghton, MI 49931

${ }^{2}$ Department of Geological and Mining Engineering and Sciences, Michigan

Technological University, Houghton, MI 49931

\begin{abstract}
Current practices for managing geotechnical assets such as retaining walls along transportation corridors are generally focused on restoring the asset after failure, as opposed to identifying and remediating hazardous conditions before failure. The main reason for lacking a proactive monitoring system is that retaining walls are numerous and assessing their condition using traditional site inspections are mostly qualitative and laborious. Monitoring systems that are qualitative tend to be subjective in nature and prone to operator bias. However, the recent advancements in optical remote sensing techniques allow for the development of accurate three dimensional (3D) models using principles of photogrammetry. These 3D models can provide a valuable alternative to traditional qualitative site inspections to determine the condition of a retaining wall, removing the subjective and bias nature of qualitative assessment methods.

* The material in this chapter will be submitted to the Journal of Computing in Civil Engineering.
\end{abstract}


This study investigates the applicability of photogrammetry in developing accurate $3 \mathrm{D}$ models of retaining walls and to use these models to quantify displacement rates in assessing the condition of retaining walls. This study also presents data collection and processing methods along with final image processing models that can be utilized and integrated into a transportation asset management program. The applicability of photogrammetry is validated using field observations and measurements from a site on the M10 Highway in Detroit, Michigan. This highway corridor was chosen based on current known retaining wall conditions which are currently experiencing significant movements in terms of tilt. The accuracy of the remotely sensed measurements is compared to ground truth data obtained by field observations, including data from inclinometers, and traditional offset measurements using a measuring tape. In order to determine the most effective data collection procedures in a similar environment to the one at M-10 highway, a small scale model of two sections of retaining walls were built in a laboratory. This model allowed photogrammetry under controlled conditions with known deflections. The results indicate that the advancements in photogrammetry show promise in generating accurate 3D surface models of retaining walls and could potentially be used for computing displacement rates if imaged within its applicable limits. 


\subsection{Introduction}

Retaining walls are a critical asset for any public and private transportation infrastructure. Every year as the demand for transportation infrastructure increases millions of square meters of retaining walls are built in the United States (Anderson et al. 2008). According to the 2013 Report Card for America's Infrastructure by the American Society of Civil Engineers (ASCE), Americas' road network contains four million miles of public roads. The report grades the condition of this aging road infrastructure with a $\mathrm{D}$, which describes the condition as poor or mediocre (ASCE 2013). In the past years there has been much evidence of the poor condition of highway infrastructure such as the collapse of the eight-lane bridge on Interstate $35 \mathrm{~W}$ in Minneapolis, MN which had catastrophic consequences (Reid 2008). Given the condition of the infrastructure, it is important for public agencies to improve and develop more efficient practices for condition assessment of assets along transportation corridors.

Transportation corridors such as highways are composed of many assets including pavements, bridges, slope side embankments, guard rails, culverts, and retaining walls among others. Retaining walls are typically designed as boundaries that set the perimeter for a space or structure (Bernhardt et al. 2003). In most cases they retain slopes or create a boundary for a space between two different elevations (DeMarco et al. 2009). As opposed to slopes or constructed embankments, retaining walls take up less space and are less disruptive to the areas along a highway or any other 
transportation corridor. Bernhardt et al. (2003) classifies retaining walls as geotechnical assets given their direct interaction with geologic structures composed of soil and/or rock.

This study presents an innovative methodology for monitoring retaining walls by using photogrammetry. Current retaining wall management methods focus on restoring the asset after failure, but little has been done to identify and remediate unsafe conditions before their incidence (Oommen et al. 2013). One of the reasons for this is that retaining walls are numerous and assessing their condition is expensive and labor intensive (Stanley 2011). The methods for condition assessment include traditional field inspections and surveys which in most cases provide a qualitative condition description. (Anderson et al. 2008). Qualitative assessments also tend to be subjective and prone to operator bias. Photogrammetry provides an efficient opportunity to quantitatively assess the condition of a retaining wall by obtaining accurate measurements of displacements over time. Photogrammetric modelling is currently being used in a wide range of applications such as monitoring river bed topography, gully erosion, rock slope stability, and glacier surface change (Westoby et al. 2012). This technique has also proven to be successful for monitoring and measuring bridge deformations (Jiang et al. 2008). In a study by Jiang et al. (2008) it was found that the field work to measure bridge geometry using photogrammetry was reduced by more than 50 percent compared to conventional surveying methods. 
Photogrammetric data can be collected from satellite, aerial, and terrestrial platforms. Aerial and satellite are considered to be long-range photogrammetric data, while terrestrial photogrammetry is considered close-range (Matthews 2008). For this study the data was collected from a terrestrial platform, which involves collecting data from multiple stationary locations. Photogrammetry requires very little equipment. Typically, a data collection will require any commercially available optical camera and a tripod. In this study a Nikon D5100 was used for data collection which currently can be purchased for around US $\$ 600$. For the application of infrastructure 3D modelling from 2D-images there are several software options used for processing. These software include, SketchUp, CityEngine, Photomodeler, and Agisoft Photoscan (Singh et al. 2014). For the processing conducted in this study, Agisoft Photoscan Professional was used. This is a stand-alone software product that performs the photogrammetric processing of 2D digital images and generates 3D spatial data in the form of point clouds and/or surface models (Agisoft 2014).

The objective of this study is to evaluate the applicability of photogrammetry for quantitative monitoring of retaining walls. To achieve this objective this study focused on monitoring a section of retaining walls on the M-10 highway located in Detroit, MI using photogrammetry. In addition, the study also performed a lab scale model evaluation to test the limits of photogrammetry for monitoring retaining walls. 


\subsection{Background}

\subsubsection{Current Methods for Retaining Walls Condition Assessment}

In 2004 only seven out of twenty three state DOT's, federal agencies, and major municipalities, which responded to a survey, acknowledged having experience with retaining wall inventories as part of a highway asset management plan (Anderson et al. 2008). In his paper “Asset Management Systems for Retaining Walls”, Anderson et al. (2008) notes that among the leading entities in retaining wall asset management are the National Park Service (NPS), Alaska Department of Transportation (AKDOT), and the Colorado Department of Transportation (CDOT). Typically an asset management is performed by the process of conducting inventory, assessing the condition of the inventory, and analyzing the results to make predictions and plan for future needs (Anderson et al. 2013).

Because the number of established retaining wall asset management plans is small, there isn't a standard process that current methods use to do such assessment. The NPS and the Federal Highway Administration (FHWA) have developed a simple and versatile asset management system for retaining walls which is cost effective and could be implemented as a model for others to adopt (Anderson et al. 2008). The performance monitoring implemented by the NPS focuses on rating the condition of a retaining wall based on specific wall features and quality measures (Anderson et al. 2008). Some of these features and quality measures include horizontal movement, 
settlement, erosion, face condition, corrosion, and drainage (Schaefer et al. 2013). The rating is based on conventional visual field inspections that only provide a qualitative assessment. Alternative techniques include the use of instrumentation such as inclinometers, strain gauges, pressure transducers, and GPS.

\subsubsection{Case Study: M-10 Highway Retaining Walls}

M-10 highway in Detroit Michigan, also known as the Lodge Freeway was constructed during the 1950-60's as a depressed highway lined with vertical cantilever retaining walls. The highway is located northwest of Detroit with paralleling service drives on each side of the highway. The highway extends from West Bloomfield Township in Oakland County on the Northside to downtown Detroit in Wayne County on the Southside and is one of the main arterial highways that provides access to and from the City of Detroit and its metropolitan surroundings. Figure 2-1 shows the location of the case study on M-10 highway, which will be referred as the Meyers Site. This site was selected due to movements that have been observed by the Michigan Department of Transportation (MDOT). Due to the magnitude of these wall movements, MDOT has initiated a monitoring program to measure the movement of the walls along the depressed section of the highway. This movement can be described as tilt, as the movement observed is happening at the top of the wall. 


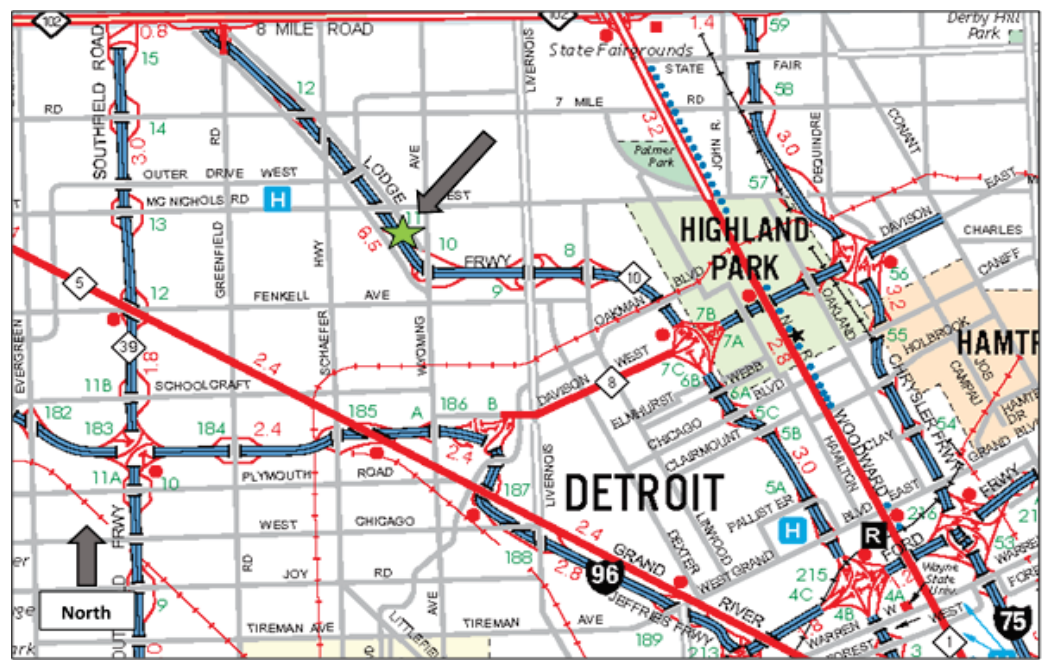

Figure 2-1 Location of Meyers Site on M-10 highway North West of downtown Detroit. Modified from MDOT Detroit Maps (2014).

The original design for the retaining walls along this highways was an experimental design by Professor William Housel of the University of Michigan (Jansson 2013). The design intended to minimize the costs of the retaining walls by reducing the size of the wall footing and introducing long tabular anchors that sloped into the embankment to resist overturning. The anchors design included post-tensioned battered caisson tie backs. The tie backs in the original design called for a $1.375 \mathrm{in}$ $(3.5 \mathrm{~cm})$ diameter high strength cable, but construction records show that during construction the cable was substituted with a solid bar (Jansson, 2013). The deviation from the original design along with increased hydrostatic pressure due to damages to the drainage system during maintenance and reconstruction in 2007 are believed to be contributors to recent wall displacements (Jansson 2013). In 2013 MDOT discovered that one of the sections of retaining wall had tilted 3 in $(7.62 \mathrm{~cm})$ towards 
the highway. A monitoring team installed tilt monitors at the expansion joints to monitor movement. After monitoring for ten months the results showed that the wall had increased its displacement by $0.37 \mathrm{in}(0.95 \mathrm{~cm})$ relative to the adjacent section and had to be replaced (Jansson 2013). Since then, MDOT has been actively monitoring other sites along M-10 highway by measuring deflection and offset at the expansion joints between the sections of retaining wall using tilt monitors and traditional measuring tapes. One of these sites is on the southbound side of the highway where Meyers Road overpasses M-10 highway (See Figure 2-1). One of the sections of retaining wall at this site has actively been tilting towards the highway. Between May 29, 2013 and August 15, 2014 the wall experienced roughly 0.79in $(2.0 \mathrm{~cm})$ displacement at its top. This displacement was measured in the field as the offset at the expansion joints relative to the adjacent walls. The total displacement at the last measurement was $3.06 \mathrm{in}(7.8 \mathrm{~cm})$. Figure $2-2$ shows the section of retaining wall between Joint 3 and Joint 4 which experienced the most deflection. The numbers of the joints were labeled by MDOT and this study uses the same numbers for consistency purposes. 


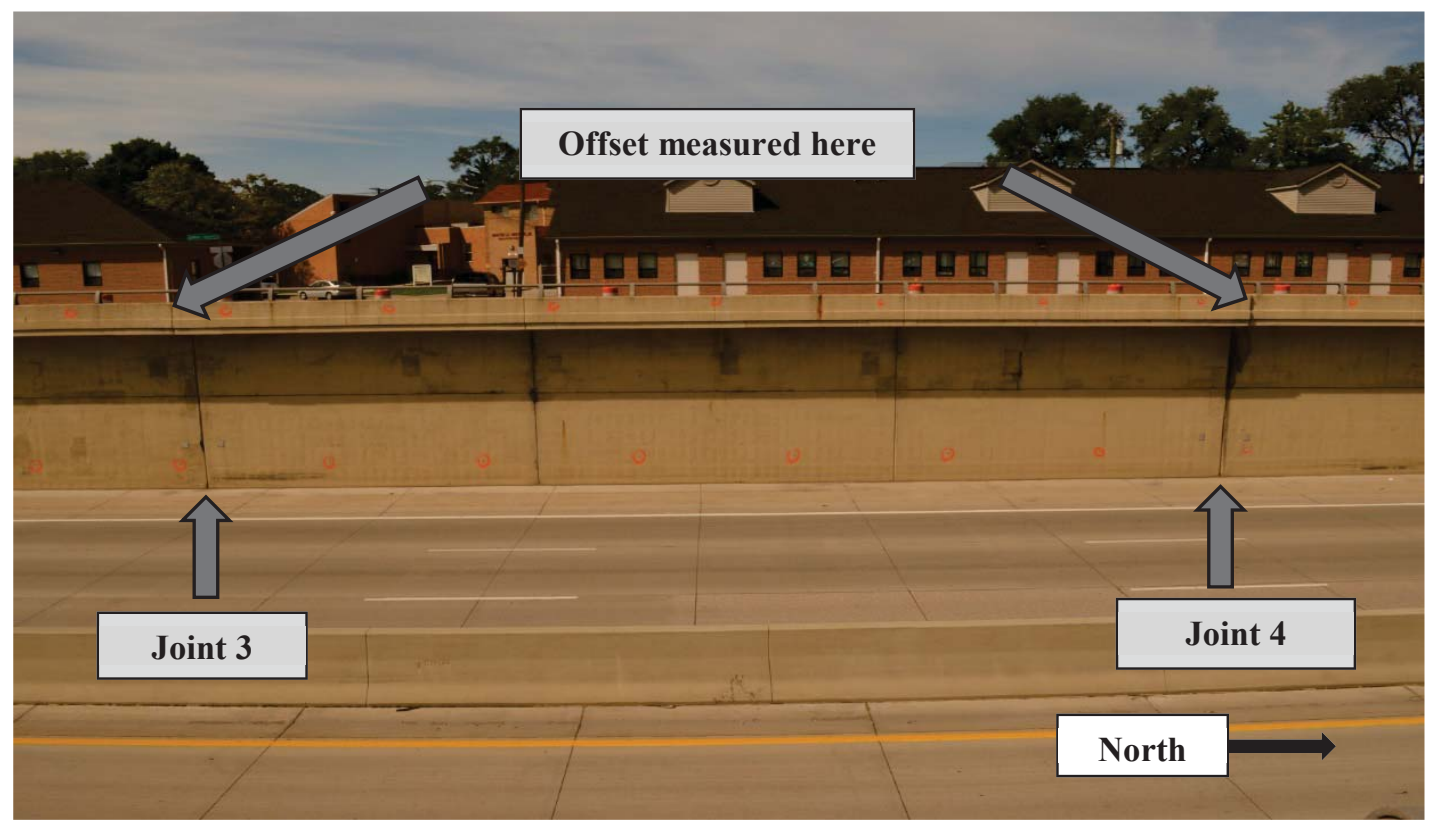

Figure 2-2 Retaining wall section at the Meyers site on M-10 Highway between Joint 3 and Joint 4 . This is the section which experienced the most displacement relative to the adjacent walls.

\subsection{Methods}

The process of using photogrammetry for retaining walls performance monitoring involves several steps. The first step is data collection. This step consists of setting up reference points and taking photographs of the retaining wall. The second step involves creating the $3 \mathrm{D}$ models using the reference points and the data that was collected. The third step is to perform a change detection between two datasets collected at two different points in time. The last step involves making measurements from the $3 \mathrm{D}$ models and analyzing them to determine and quantify the performance characteristics of a retaining wall over time. 


\subsubsection{Principles of Photogrammetry}

Recent advancements in commercial optical sensors and photogrammetric processing software provide a simple and inexpensive technology that can be used for retaining wall performance monitoring. The American Society for Photogrammetry and Remote Sensing defines photogrammetry as “...the art, science, and technology of obtaining reliable information about physical objects and the environment through process of recording, measuring, and interpreting photographic images and patterns of recorded radiant electromagnetic energy and other phenomena." (Wolf and Dewitt 2000). In this study photogrammetric surveying consists of obtaining measurements from 3D models created from 2D images. The process involves taking photographs of the object of interest from at least two different locations. From each location there is a line of sight that runs from each point on the object to the perspective center of the camera. The images from two consecutive locations need to have a certain overlap and typically 60 percent overlap is used. This allows the location of a point in 3D space to be determined by using the principle of triangulation and mathematically finding the point of intersection between different lines of sight (Jauregui et al. 2003).

The method used in this study which is the most common method to acquire images for 3D modeling is the Pinhole Camera Model (Wohler 2009). The pinhole camera model uses the camera lens to represent the camera's optical center which corresponds to a point located between the 2D image plane and the 3D scene (Wohler 
2009). Figure 2-3 illustrates the geometric layout of the pinhole camera model (Wohler 2009).

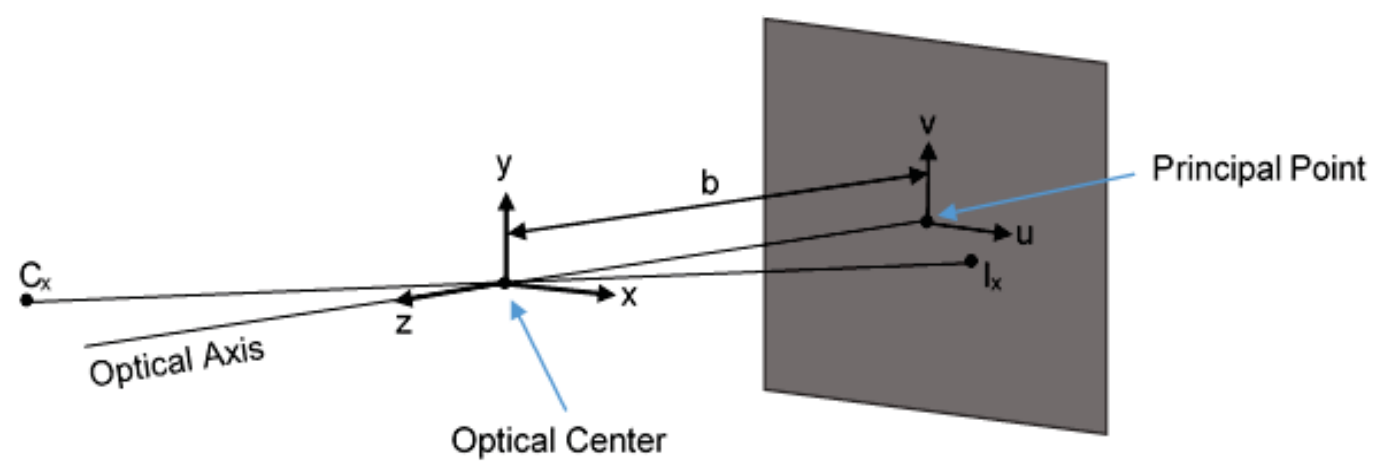

Figure 2-3 Pinhole camera model. Modified from Wohler (2009).

The image plane coordinates (Ix) and the camera coordinates $(\mathrm{Cx})$ are related to each other since both have the principal point as their origin. The point $\mathrm{x}$ on the image plane will have coordinates $I_{x}$ as a function of the vectors $\mathrm{v}$ and $\mathrm{u}$ (Wohler 2009). These vectors in turn will relate to the $(\mathrm{x}, \mathrm{y}, \mathrm{z})$ coordinate system by the principal distance denoted $\mathrm{b}$ in Figure 3-2. The following equations show the relationship between $\mathrm{I}_{\mathrm{x}}$ coordinates and the camera coordinates (x,y,z) (Wohler 2009).

$$
\begin{aligned}
& u=-b\left(\frac{x}{z}\right) \\
& v=-b\left(\frac{y}{z}\right)
\end{aligned}
$$

A detailed discussion on the mathematical background for the pinhole camera model can be found in Chapter 1 in Wohler (2009). 


\subsubsection{Laboratory and Field Work - Data Collection}

In order to better understand how to determine the deflection by taking photographs it is important to find and understand the best data collection procedures. Agisoft Photoscan Professional has a set of general guidelines for data collection procedures, but because the software is used for a wide range of applications these guidelines are broad and don't consider multi-temporal data sets for change detection. To narrow down on the best practices for data collection at the Meyers site, a small scale model was built in a laboratory at Michigan Tech.

The model was built to simulate two sections of retaining wall with an expansion joint. The model was constructed using two individual sections with each section on a frame that holds a four feet by eight feet sheet of oriented strand board (OSB). The strand board is covered with sheets of insulating foam board. The foam board sheet is fixed at the bottom by two hinges which allow it to tilt outward to simulate deflection. Once the deflection is determined, the top of the foam board is held in place by a cord attached to the foam board with a screw and the other end is secured to the structure's frame. Figure 2-4 shows the lab scale model. Part (b) of Figure 2-4 also shows the reference points used for registration in Agisoft Photoscan. 


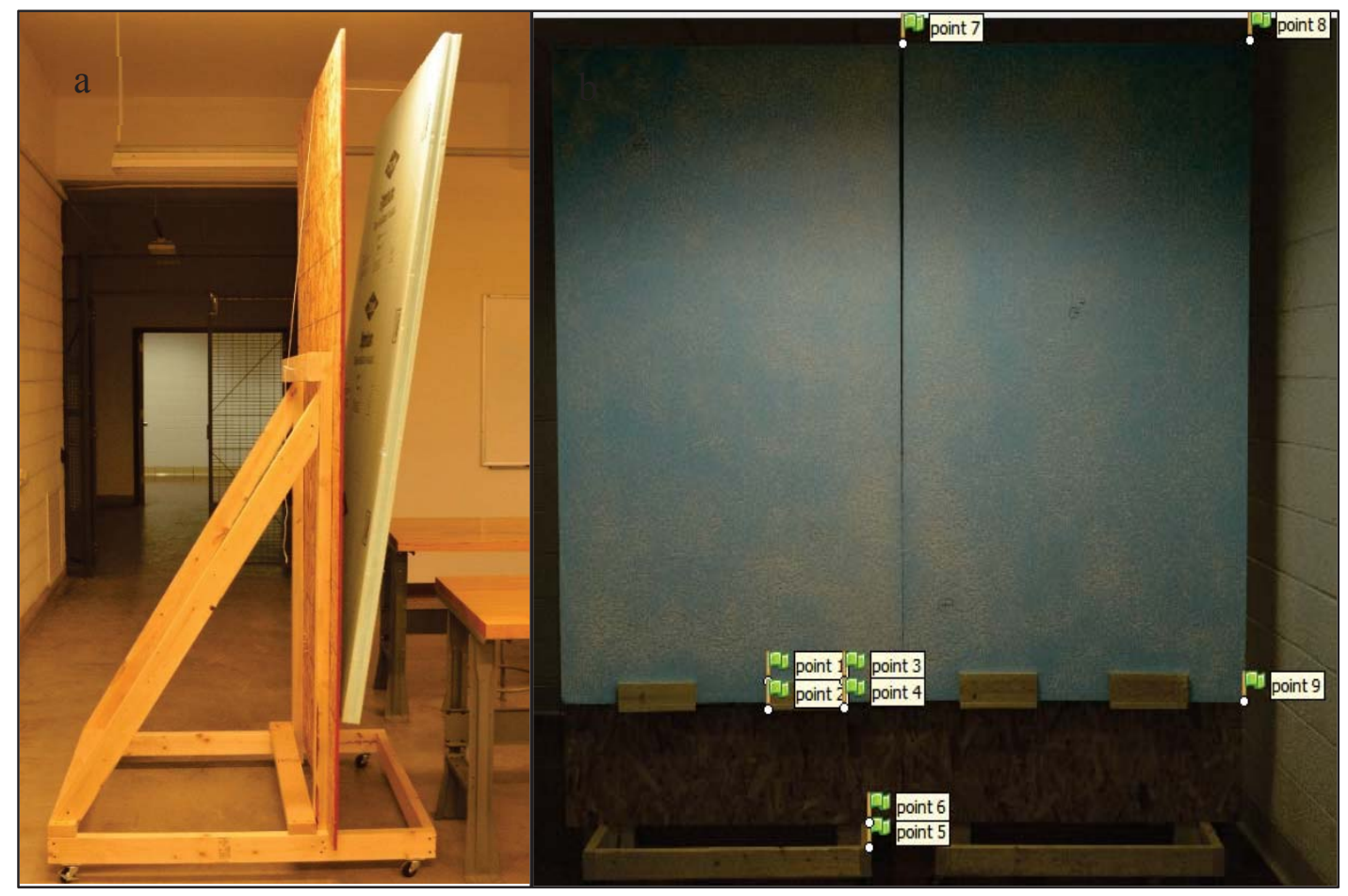

Figure 2-4 Retaining walls small scale model. (a) Single unit structure with the panel rotated about a bottom hinge to simulate deflection. (b) Scaled model consisting of two units to simulate two sections of retaining wall meeting at an expansion joint.

A Nikon D5100 camera was used for the laboratory and field work. This camera allows 16.2 megapixels pictures, and has digital single lens reflex (D-SLR), and AFS DX $18-55 \mathrm{~mm}$ with vibration reduction (VR) lens. The first step in the process is to calibrate the camera. The calibration factors used include lens focus, shutter speed, and aperture, which will depend on the size of the target, distance between the target and the camera stations, as well as lighting (Westoby et al. 2012). The laboratory tests consisted of collecting data from a range of distances from 20-100ft. The focus of the camera was set to $35 \mathrm{~mm}$ for $20 \mathrm{ft}$ or closer and $55 \mathrm{~mm}$ for distances greater than $20 \mathrm{ft}$. 
Once the manual focus was set the camera was positioned such that a distinguishable small feature in the model was at the center of the frame. With the camera fully zoomed-in to this feature, the autofocus was used to refine the focus process. Finally, once the camera was focused on the small feature the autofocus was turned off and these settings were kept constant for the rest of the data set collection. It is important to note that the camera calibration settings should be fixed for an entire dataset at a specific distance.

The next step in the data collection process is to take the photographs. For this step the photographs should be taken perpendicular to the model. Each photograph should show a section of the model. This is done by starting at one end of the model and walking parallel to it and taking photographs at different points in this trajectory until the other end of the model is reached. In some cases the object will fit in one frame of the camera, but it is still necessary to take the pictures in using this procedure so that the processing software has enough information to perform accurate triangulation calculations. The photographs should be taken so that there is at least 60 percent overlap between the previous photograph and the current one. In the case of the retaining wall scaled model, one photograph could capture the entire model, so not very images (6-10) where needed to create an accurate 3D model.

In order to accurately perform a change detection it is imperative to georeference the 3D models. The georeferencing process starts in the data collection step. A local 
coordinate system is created using several reference points that are located on the structure or any fixed location that appears in the photographs. For this study the reference points were located on the model structure and were surveyed by using a traditional measuring tape. During the georeferencing process it is important to consider that the reference points are sufficiently well distributed in 3D space relative to the model size. This will provide more precise scale information to the processing software. Also, for the purposes of change detection, during data collection it is important to note that each photograph should contain at least one reference point that is in another image. This allows the processing software to accurately reference points in all the images in order to assign a correct location in space for each of the points in the 3D model.

Now that the basic considerations for the data collection procedures have been obtained from the lab testing, these were put into practice at the Meyers site. Some minor adjustments were done to calibrate the camera due to the larger size target and different lighting conditions. The manual focus ranged from $18-35 \mathrm{~mm}$ and the same steps from the laboratory work were followed for the autofocus process. Other camera settings such as shutter speed, aperture, and ISO speed varied due to the lighting conditions but typically an aperture of f/8, ISO Speed of 100, and shutter speed of $1 / 200^{\text {th }}$ of a seconds were used. The section of retaining wall with the most offset deflection is between Joint 3 and Joint 4 shown in Figure 2-2. This section spans 200ft between the expansion joints and $20 \mathrm{ft}$ in height from the roadway elevation to the top 
of wall. The camera stations for the data collection were located on the opposite side of the highway on the service drive $100 \mathrm{ft}$ away.

To set up the coordinate system, reference points were marked on the retaining wall section between Joint 3 and 4 as well as the adjacent sections. The reference points consisted of spray-painted circles with crosshairs in the middle. Each reference point was surveyed by an MDOT surveying crew using the Michigan State Plane Coordinate system. The survey equipment included a Leica TS15 total station in the reflector-less mode. It is important to note that the points were set up in the early stages of this study, thus the principle of sufficient distribution in 3D space was not considered at that time.

Once the reference points were set up, the next step consisted of taking photographs from the service drive on the opposite side of the highway. This procedure consisted of setting the camera perpendicular to one end of the retaining wall and continuously capturing images while moving parallel to the wall until the other end of the retaining wall was reached. Each photograph in a dataset has 60 percent or more overlap between adjacent images. One of the challenges with the data collection was to take the photographs in gaps between vehicles in order get a clear view of the entire wall. For each field trip MDOT closed down one of the service drive lanes to allow for a safe area for the data collection. 


\subsubsection{D Modelling and Point Cloud Creation}

The next step in the process is the creation of a $3 \mathrm{D}$ models which in this study are point clouds. The software Agisoft Photoscan Professional edition was used for this purpose. This software was chosen because of its ability to accurately process $2 \mathrm{D}$ images into 3D point clouds and/or surface models with a few simple and user friendly steps. Also, it allows the user to export the final results in a wide range of file formats supported by the most common GIS and 3D modeling software. The process to build a point cloud is simple and fast depending on data set sizes and computing capabilities. Agisoft recommends that a Windows system user should have Windows XP or later with an Intel Core i7 processor combined with $12 \mathrm{~GB}$ of RAM. With these capabilities Agisoft Photoscan Professional will allow to process a model with up to 200-300 10MPx photographs (Agisoft 2014). Most of the data used in this study was processed using a laptop with a RAM of 6GB and an Intel Core i5 processor with Intel HD Graphics Family. The datasets ranged from 5-15 16 Megapixel photographs.

To process a dataset of photographs into a useable and exportable point cloud Agisoft Photoscan Professional uses three main steps. In the first step, the photographs are input into the software in any of the following formats TIFF, JPEG, BMP, PNG, PPM and JPEG MPO. Once the data is input the software defines the structure of the project and prepares it for processing. In the second step the software takes the reference points or ground control information from the photographs and triangulates it to best align all the images in the dataset. The software then used the pinhole camera model 
to find the location of each point in 3D space. The result from this step is a $3 \mathrm{D}$ model in the form of a point cloud which is termed a "sparse cloud". Finally the sparse cloud is further refined by increasing the density of the points by a process of interpolation. This higher resolution point cloud called "dense cloud" is the final 3D model. Agisoft PhotoScan allows this point cloud to be exported as GeoTIFF elevation data, Arc/Inpho ASCII grid, and XYZ file formats which are compatible with other software for further processing (Agisoft 2014).

\subsubsection{Multi-temporal Model Registration and Point Cloud Comparison}

The next step in this process includes a point cloud comparison. A point cloud comparison procedure performs a change detection by computing the distance of a point cloud to another reference point cloud (Girardeou-Montaut et al. 2005). In order to compute the distance between two point clouds, these need to be accurately registered.

The registration of the multi-temporal models permits the correct and accurate alignment of the $3 \mathrm{D}$ models so that the change detection process can accurately capture any changes in the condition of the wall. If the registration is inaccurate, the point cloud comparison will incorrectly highlight the unaligned areas between the $3 \mathrm{D}$ models as change (Cloud Compare 2014). In this study, Cloud Compare Version 2.5.4.1 and Matlab software were used to register the models created in Agisoft Photoscan Professional (Mathworks 2014). Cloud Compare is an open source 
software for visualizing, processing and analyzing three-dimensional point clouds (Cloud Compare 2014).

An accurate registration can be conducted using several different methods. The most simple and accurate registration is done by using the georeference system from the models created in Agisoft Photoscan Professional. If the point clouds have an accurate georeferencing system they will automatically register in $3 \mathrm{D}$ space once they are brought into the interface of the modeling software. When the georeference systems are not accurate the point clouds will not align correctly and further registration is needed. The two standard techniques for registration are point matching and Iterative Closest Point (ICP) algorithm (Girardeau-Montaut et al. 2005). Point matching consists of picking several point pairs from common and visible locations on both point clouds such as corners of objects and using these to register the models. The ICP algorithm is used to minimize the distance between two point clouds that are not accurately registered. The ICP algorithm pairs each individual point in the compared point cloud to its nearest neighboring point in the reference cloud forming correspondence pairs. The algorithm then uses a point-to-point error metric where the sum of the squared distance between points in every correspondence pair is reduced to a minimum (Besl and McKay 1992; Low 2004). This process is repeated until the error stops changing or it becomes lower than the threshold (Low 2004). Additional details on the mathematical background of ICP refer to Besl and McKay (1992). 
The accuracy of the georeferencing is based on the 3D spatial distribution of the physical reference points relative to the size and depth of the target. The reference points should be well distributed in all three dimensions as shown in Figure 3-5. The reference points at the Meyers site have a relatively good distribution in one plane but not in the third dimension, so the georeference for each model was not very accurate. The point clouds from the laboratory scale model were registered based on an accurate georeferenced models. On the other hand, the models from the M-10 Meyers site needed better registration.

For the M-10 Meyers site two registration processes were used in Cloud Compare that allowed for an accurate alignment of the point clouds. The first registration was based on the georeferencing of the models, which was inaccurate, so point matching was used to further refine the registration. This process consisted of picking point pairs on well-defined features on the wall such as corners of the tilt monitor plates and corners of the wall. In Matlab the registration process utilized the ICP algorithm. It is important to note that the changes between the sections of retaining wall are relative and individual sections have different rates of change. Because of this, registration processes such as point matching and ICP have to be used with careful consideration in order to avoid disturbance of true differences. With this in mind, the point matching and ICP registration functions were performed on only one section of retaining wall which we assume to have not moved. 
In the point cloud comparison process one of the models is chosen to be a reference for the other models to be compared to. For the purposes of this study the model from the data collected at the earlier data collection date was used as the reference model. There are several ways to determine the changes between the datasets after registration. In Cloud Compare this step was done by using Cloud Compare's Cloud to Cloud comparison function. This function calculates the distances between two point clouds by assigning each of the compared cloud points the distance to its nearest neighbor point in the reference cloud (Cloud Compare 2014). The output of this function is the compared cloud where each point has the value that represents the distance to its nearest neighbor in the reference cloud.

The Matlab software change detection process consisted of computing the distances between the point clouds by using a Point to Surface algorithm. In this process a surface plane is "fit" to the earlier of the two datasets. This plane is created by using the points from the section of retaining wall that was used in the ICP process for registration, in this study it was the section of wall between joints 3 and 4 (Mathworks 2014). For more details on how the surface is created refer to (Girardeau-Montaut 2005). The distances from the points in the compared cloud to the reference surface are then computed. The changes between the two 3D models are then highlighted on the sections of retaining wall which were not used for the ICP process. 


\subsection{Analysis and Results}

The processing of the small scale model proved to be applicable to the field data with some minor variations. Although the techniques applied in the field were heavily based on the lab work, there are a few important issues that should be considered during the analysis of the results after the processing steps. The first issue is that difference in distance between the target and the camera has an effect on accuracy. The second issue is that the number and location of the reference points has an important impact on the georeferencing accuracy of the three-dimensional models. The last issue is that the deflections on the small scale model are simulated by rotation

of the top with respect to a fixed hinge at the bottom of the wall. Although the retaining walls at the Meyers site have experienced similar movement, the retaining walls have also moved horizontally as a rigid body towards the highway where both the top and the bottom of the wall moved the same amount towards the highway. This is based on field observations by MDOT inspectors.

\subsubsection{Laboratory Scale Model Deflection Measurements}

To investigate the effect of distance between the camera and the target, data sets were collected from the small scale model from 20-100ft in intervals of $20 \mathrm{ft}$ as well as one at $50 \mathrm{ft}$. The maximum distance of $100 \mathrm{ft}$ was used because this is the same distance at which data was collected at the Meyers site. Two sets of data were taken at the following distances; $20 \mathrm{ft}$, 40ft, $50 \mathrm{ft}, 60 \mathrm{ft}, 80 \mathrm{ft}$, and $100 \mathrm{ft}$. 
The first dataset was collected from the model with zero deflection and the second was collected from the model in which one panel was rotated to have a deflection of $3.25 \mathrm{in}$ at the top with respect to the adjacent panel. The results from processing this data is presented in Figure 2-5.

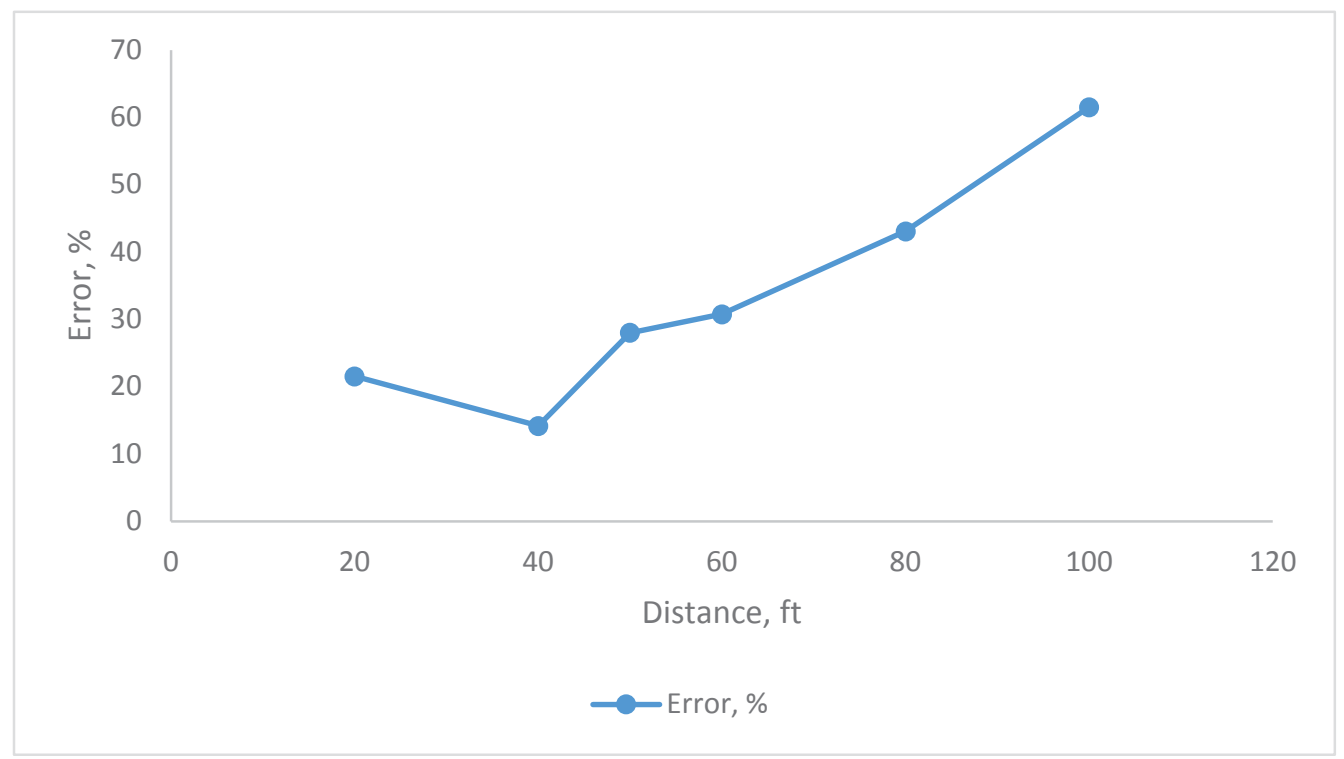

Figure 2-5 Curve of percent error with respect to distance between optical camera and the surface of the wall of the small scale model after change detection processing of the point clouds.

The error shown in Figure 2-5 represents the total error after data collection and change detection. Figure 2-5 shows that the accuracy of the 3D models is reduced as the distance increases between the camera and the retaining wall during the data collection. At the distance of $100 \mathrm{ft}$ the error in depth after data collection and processing is roughly 60 percent. This means that the change detection results from the lab model showed a deflection of 2 in as opposed to the true deflection of $3.25 \mathrm{in}$. 
It is important to note that the focal length for the data collected at $20 \mathrm{ft}$ was set at $35 \mathrm{~mm}$ and for all the rest of the distances it was set to $55 \mathrm{~mm}$ which is the maximum focal length for the lens used in this study. The difference in focal length is because at $20 \mathrm{ft}$ the focal length of $55 \mathrm{~mm}$ is too narrow and the reference points would have not been visible in every photograph. Since the reference points provide the scale and georeferencing for the 3D model it is important to have as many as possible in every image to get better accuracy. The error was measured by computing the average of the values of the points at the top of the scaled model's panel and compared with the deflection of $3.25 \mathrm{in}$.

The error presented in Figure 2-5 can be attributed to the accuracy of the camera lens and pixel size of the image with respect to depth as well as software computational errors while processing the data. To verify this, a simple study was conducted to check the accuracy of the camera with respect to distance. This was done by calculating the distance accuracy specific to the Nikon D5100 camera with the $18-55 \mathrm{~mm}$ lens used in this study. The following relationships are suggested by ADAM Technology (2014), to calculate the image-plane $\left(\sigma_{\text {wall plane }}\right)$ and distance accuracy $\left(\sigma_{\text {depth }}\right)$ of a Nikon D5100 camera with the $18-55 \mathrm{~mm}$ lens. The variable in equations $1-3$ are focal length (f), distance from camera to the wall (d), distance between camera stations where the photographs were taken (b), and pixel accuracy (P). 


$$
\begin{aligned}
& \text { Pixelsize }_{\text {wall plane }}=\left(\frac{d}{f}\right) * \text { Pixelsize }_{\text {image }} \\
& \sigma_{\text {wall plane }}=P * \text { Pixelsize }_{\text {wall plane }} \\
& \sigma_{\text {distance }}=\left(\frac{d}{b}\right) * \sigma_{\text {wall plane }}
\end{aligned}
$$

At a distance of $100 \mathrm{ft}$ with a $55 \mathrm{~mm}$ lens the distance accuracy of the pixel is $1.2 \mathrm{in}$ with respect to its true position. The size of a pixel for a Nikon D5100 with an $18 \mathrm{~mm}$ to $55 \mathrm{~mm}$ lens is $4.78 \mu \mathrm{m}$ by $4.78 \mu \mathrm{m}$ and the pixel accuracy was estimated to be $1 / 3$. Figure 2-6 shows the theoretical depth accuracy of the Nikon D5100 with a focal length of $55 \mathrm{~mm}, 200 \mathrm{~mm}$, and $300 \mathrm{~mm}$. The distance between the camera positions was consistently about $1 \mathrm{~m}$. As expected the curves are consistent in showing that the accuracy is reduced as the distance between the camera and the retaining wall are increased. 


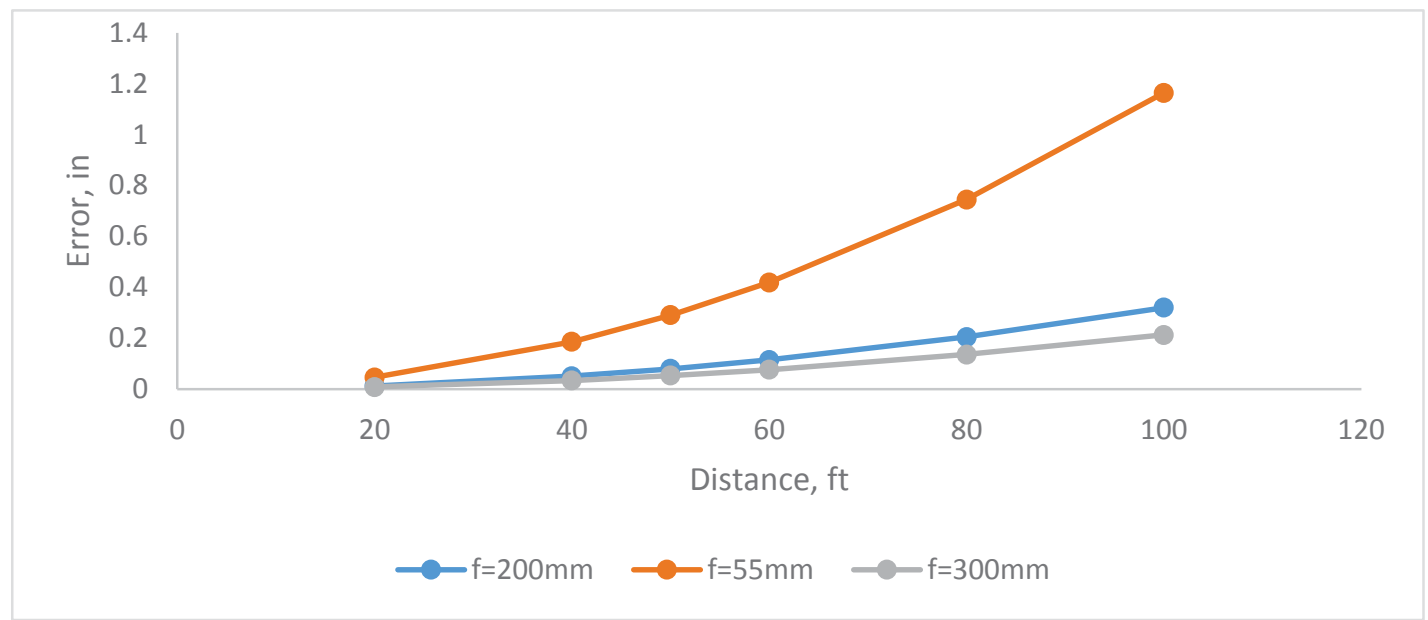

Figure 2-6 Curve of depth accuracy at various distances for Nikon D5100 using several focal lengths.

To get a better understanding of the 3D model accuracy, 3D models for distances $20 \mathrm{ft}$ to $100 \mathrm{ft}$ with a deflection of 3.25 in were processed using Matlab. Using a focal length of $55 \mathrm{~mm}$ the results show that the deflection can be measured for data collected within $40 \mathrm{ft}$ of the retaining wall. For distances greater than $40 \mathrm{ft}$ the error becomes significant and the true deflections cannot be accurately determined. Figure 2-7 shows the plots of the plan view of the $3 \mathrm{D}$ models created from the scale model where the panel on the right (plan view) was deflected $3.25 \mathrm{in}$. The plots show that from 20 to $40 \mathrm{ft}$ the deflection can clearly be defined and quantified, but at distances of $50 \mathrm{ft}$ and greater the deflection cannot be determined due to a combination of the lens's and processing errors. 

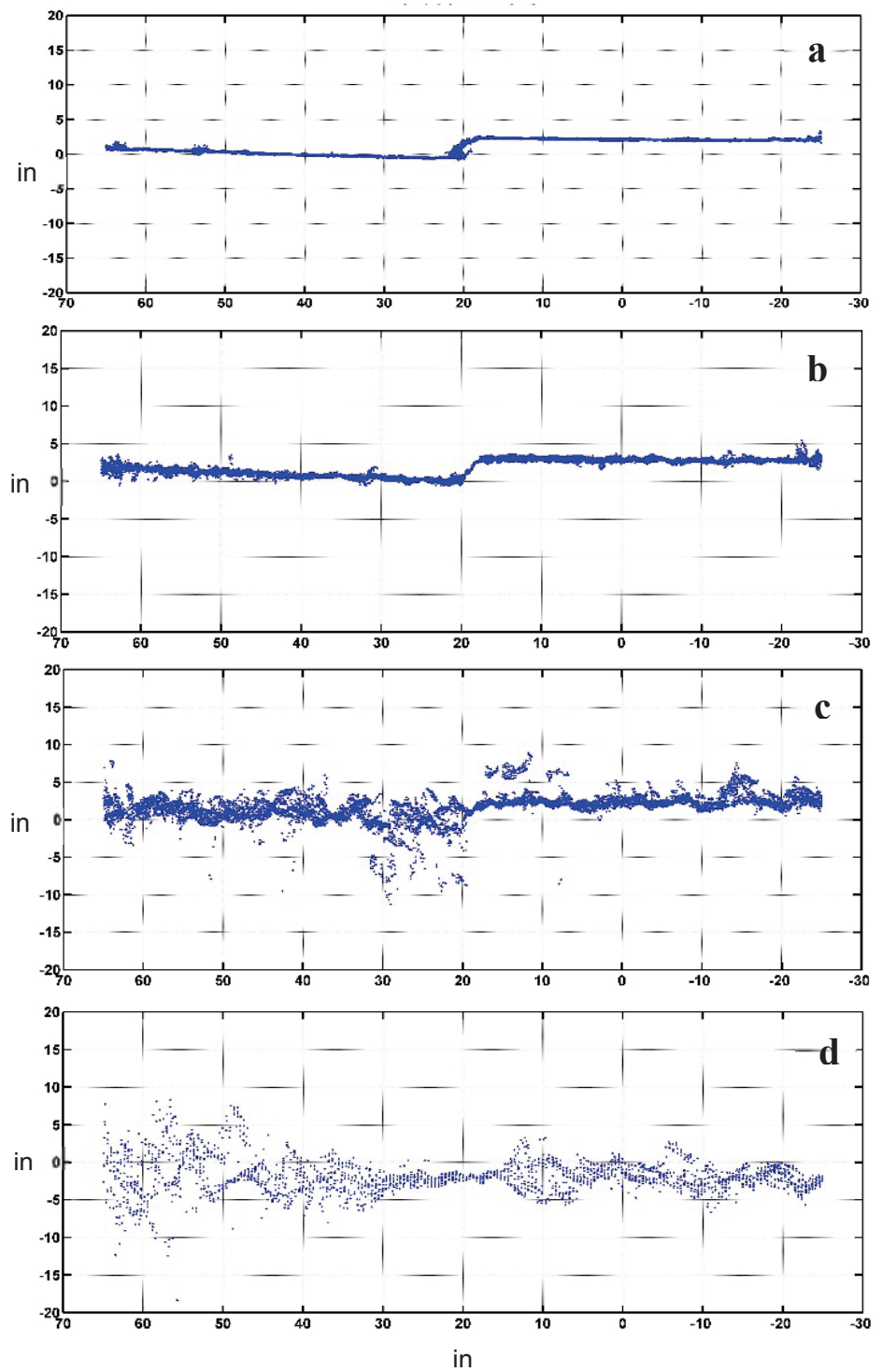

Figure 2-7 Plan view of the top of the lab model point clouds with the right panel having a deflection of $3.25 \mathrm{in}$. (a) Point cloud at $20 \mathrm{ft}$ with $35 \mathrm{~mm}$ focal length. (b) Point cloud at $40 \mathrm{ft}$ with $35 \mathrm{~mm}$ focal length. (c) Point cloud at $50 \mathrm{ft}$ with $55 \mathrm{~mm}$ focal length. (d) Point cloud at $100 \mathrm{ft}$ with $55 \mathrm{~mm}$ focal length. 
Although the deflection results are unreliable at distances greater than $40-50 \mathrm{ft}$, the $3 \mathrm{D}$ models are still able to capture the trend in movement. Figure 2-8 shows the deflection trends for the point cloud datasets presented in Figure 2-7. The lines in Figure 2-8 represent the top of a plane that was fit through each panel's point cloud. The joint between the laboratory scale model panels is at 19in on the horizontal axis and the offset was set at 3.25 inches for the panel on the left.

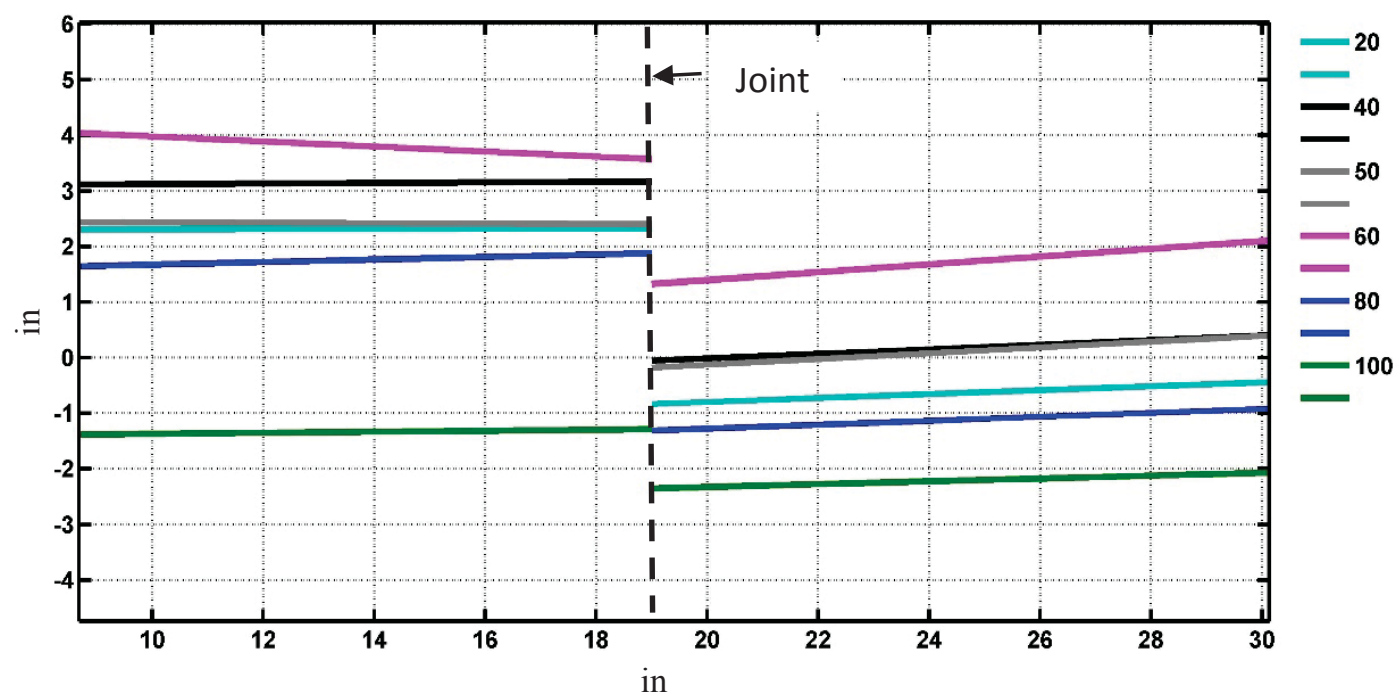

Figure 2-8 Plan view of the top of the planes fit through the 3D point clouds with a 3.25 in deflection. The joint is at 19 inches on the horizontal axis.

\subsubsection{M-10 Deflection Measurements}

Three datasets were used in this study to analyze the movement of the retaining walls at the Meyers site. The first dataset was collected on Mach 11, 2014, the second data set was collected on June 23, 2014, and the last dataset was collected on August 15, 
2014. To get a better understanding of the retaining wall movement, the 3D models from March and June were compared and the 3D models from March and August were also compared. The resulting comparisons show a consistent trend of movement that indicate that most of the horizontal movement occurred at Joint 4 in contrast with the field measurements that indicate same amount of deflection at Joint 3 and Joint 4.

The displacement offset between June 24, 2014 and August 15, 2014 measured at the top of Joint 3 and Joint 4 was 0.20 in $(0.50 \mathrm{~cm})$. Ideally the offset would include results dating back to the fist data collection on March 11, 2014, but unfortunately no deflection measurements were made during this time. MDOT also monitored the deflection using tilt meters that indicate the offset at joints 3 and 4 was 0.22 in $(0.55 \mathrm{~cm})$ from March 13, 2014 to August 15, 2014. Given the limitations of this method, the analysis of the 3D models was not able to capture this small offset, but it still provided some promising trend in the movements of the retaining wall. Figure 29 shows the results from the point cloud comparisons. 


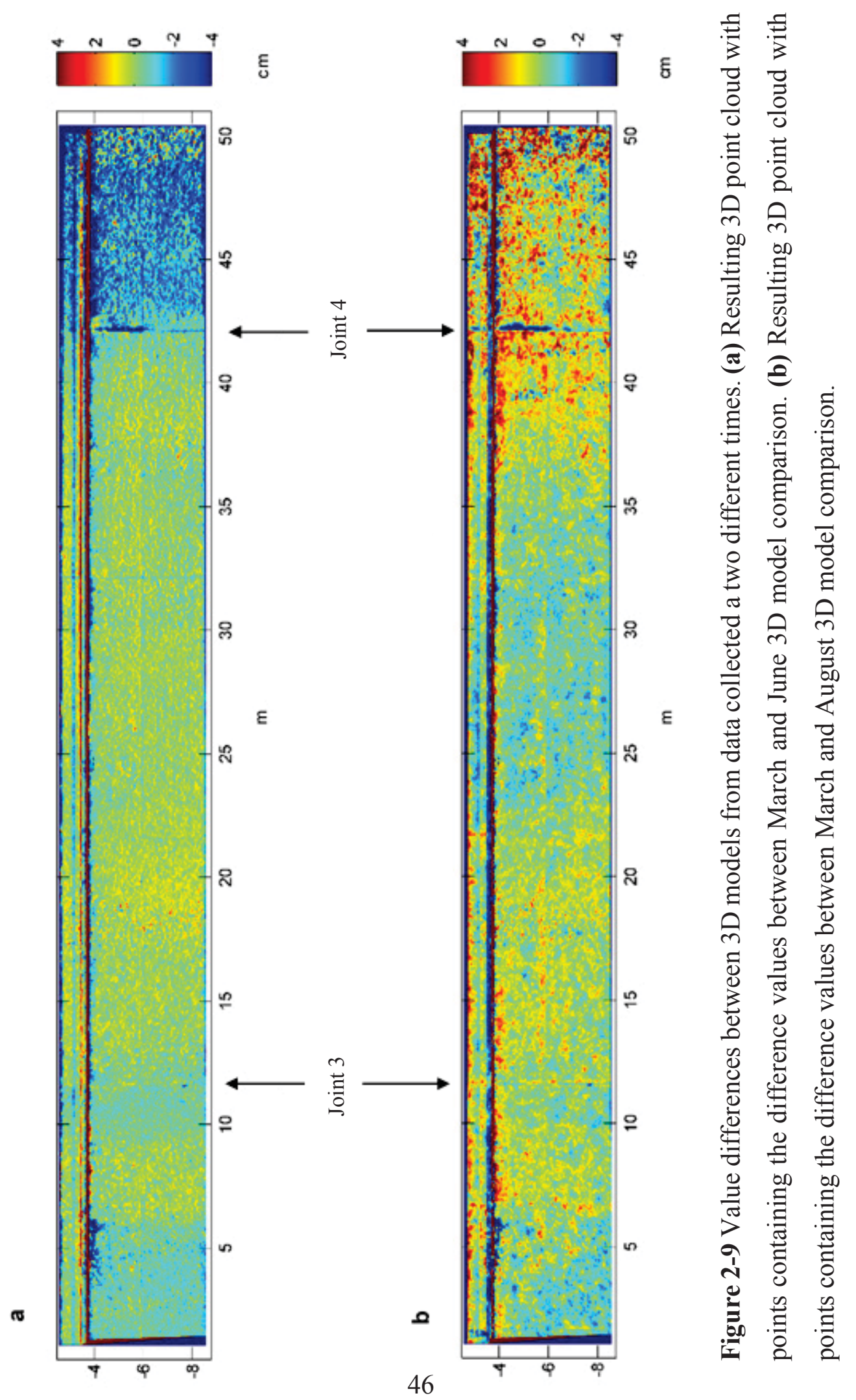




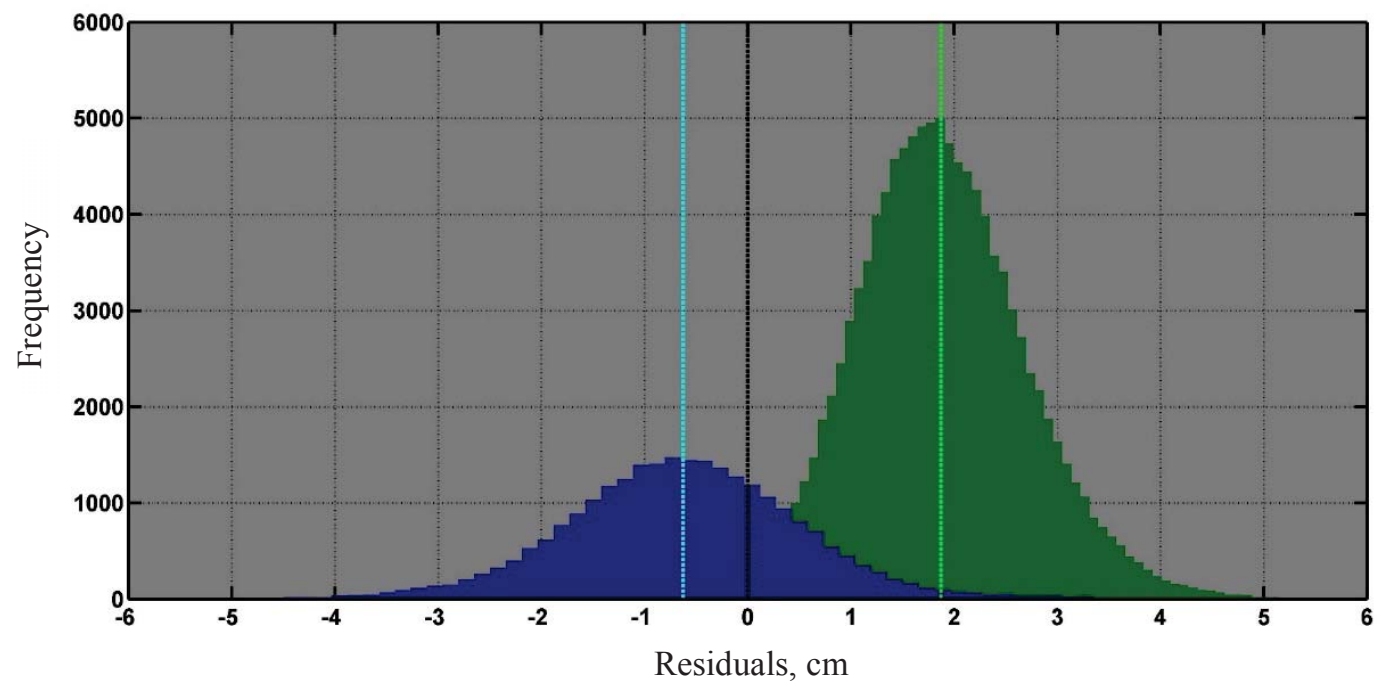

Figure 2-10 Histogram showing offset residuals for the retaining wall section to the right of Joint 4. The green residuals between March and June show 0.75 in $(1.9 \mathrm{~cm})$ horizontal movement towards the highway. The blue residuals between March and August show 0.24 in $(0.60 \mathrm{~cm})$ of movement away from the highway.

Figure 2-10 show the resulting offsets measured from the 3D models at Joint 4 . The mean of the distribution (shown in color green) represents the deflection at Joint 4 between March and June. This measurement indicates that the retaining wall between joints 3 and 4 moved $0.75 \mathrm{in}(1.9 \mathrm{~cm})$ towards the highway. The mean of the blue distribution indicates that between March and August the wall moved 0.24in $(0.60 \mathrm{~cm})$ away from M-10 highway. The total movement between June and August is the distance between the means of the blue and green distributions. This distance indicates that the wall moved 1 in $(2.5 \mathrm{~cm})$ away from the highway. Based on the low accuracy of the 3D model georeferencing and processing, these offset values are unreliable due to their higher percentage of error. 
Although these values are unreliable there are some important considerations that arise from the final results that provide an opportunity for future work. First, it is important to consider that the offset from the 3D models was only able to be measured at Joint 4 only and not at Joint 3 in both change detection processes. The laboratory error-at-distance study shows that at $100 \mathrm{ft}$ small deflection measurements such as the one at the Meyers site cannot be captured. This is confirmed in the results shown in Figure 2-9 for joint 3 and 4 where the offset movement was not captured at Joint 3, and at Joint 4 the offset measurement contains a large error. Although the offset measurements are not accurate, the results show a consistent trend in movement for the value differences of March-June and March-August. The trend from the 3D models indicates that the retaining wall moved horizontally at the top and at the bottom when the field offset measurements clearly indicated that the wall only moved at the top. Given these considerations a possible explanation for this trend is that the sections of retaining wall on both sides of Joint 4 are moving toward the highway more so than at Joint 3 . This movement could be occurring at the same time as the walls are also moving relative to one another. This movement is best described in Figure 2-11 parts (a) and (b). 

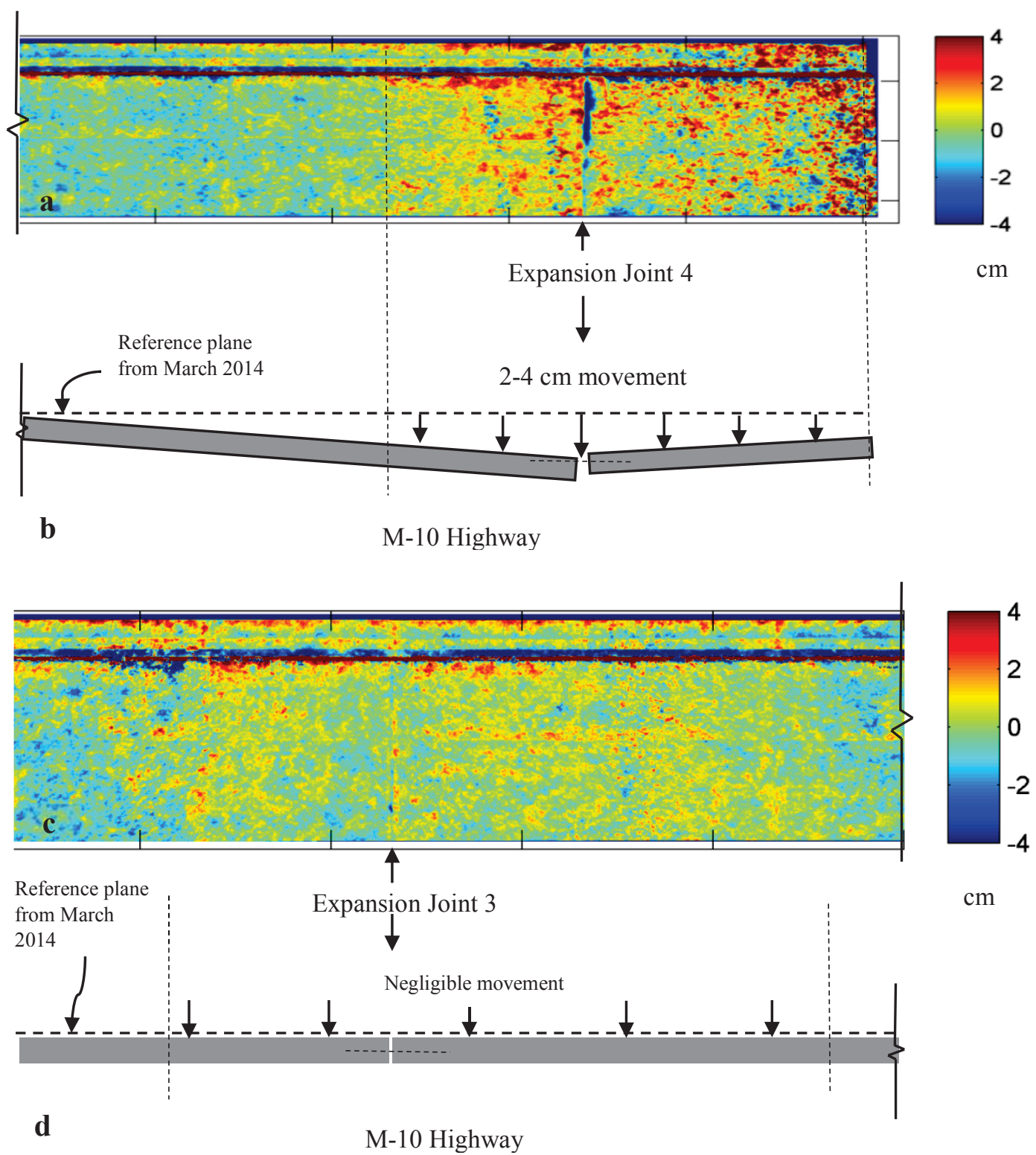

Figure 2-11 (a) Value differences between March and August for the area around Joint 4. (b) Plan view of the retaining wall sections on both sides of Joint 4 showing the potential horizontal movement towards the highway. (c) Value differences between March and August for the area around Joint 3. (d) Plan view of the retaining wall sections on both sides of Joint 3 showing negligible horizontal movement towards the highway. 
Part (a) in Figure 2-11 shows the change detection values between March and August. The resulting values show 2 - 4cm horizontal movement towards M-10 highway on both sides of Joint 4. In part (b) of Figure 2-11 a plan view of the same area is shown. The figure shows the horizontal movement with respect to the position that the wall occupied in March, which is represented by the horizontal dashed line. Parts (c) and (d) show that there isn't significant horizontal movement towards M-10 in the area around Joint 3.

\subsection{Conclusions and Future Work}

As with other geotechnical assets retaining walls are often overlooked. Asset management systems that include inventory, condition assessment, and analysis for future predictions are very few and in many cases nonexistent. From these, only a select few monitor geotechnical assets such as retaining walls. Currently asset condition assessment is done by using traditional methods which in most cases only provide a qualitative assessment. This study introduces photogrammetry which has the ability to provide a quantitative approach for assessing a retaining wall. The position of the retaining wall can be accurately quantified by obtaining measurements from 3D models created from 2D photographs.

The study presented in this paper shows that photogrammetry has the ability to capture offsets and horizontal displacements on retaining wall. The process to obtain these results is relatively simple and consists of taking photographs with a standard 
optical camera at two different points in time, building 3D models, and finally comparing the models to extract quantifiable information from them. The accuracy of this method depends on the distance between the sensor and the retaining wall at the time of data collection. It also depends on the focal length of the camera's lense and the location of the reference points in 3D space. The results from the study show that accurate relative offset measurements can be obtained when the photogrammetric data is collected within $40 \mathrm{ft}$ of the retaining wall for the camera system used. At distances greater than $40 \mathrm{ft}$ the accuracy of the $3 \mathrm{D}$ models is reduced. While the accuracy of relative offset measurements is not as reliable for the Meyers site at 100ft, the results shows consistent and strong evidence of horizontal displacement around Joint 4. This evidence suggests that both sections of retaining wall on either side of Joint 4 are moving towards M-10 highway, however, this could not be validated using the field measurements from this study.

Future work should focus on increasing the accuracy of this 3D models by using a camera with lenses that have a higher focal length for data collection since this will increase the depth accuracy for individual points on the 3D model as shown in Figure 2-6. Future work should also be conducted to improve the location of the reference points in 3D space, and most importantly develop a more efficient way for field work. Finally, more work should be done to come up with field techniques that can be used to validate the non-relative horizontal movement results from the Meyers site. 


\section{REFERENCES}

Agisoft PhotoScan Professional. (2014). "Agisoft PhotoScan Capabilities". $<$ http://www.agisoft.ru> (Aug. 29, 2014).

American Association of State Highway and Transportation Officials (AASHTO). (2013). "AASHTO Transportation Asset Management Guide: A focus on Implementation". AASHTO, Washington, DC.

American Society of Civil Engineers (ASCE). (2013). “2013 Report Card for America's Infrastructure". ASCE, Reston, VA.

Anderson, S. A., Alzamora, D., and DeMarco, M. J. (2008). “Asset Management Systems for Retaining Walls". Biennial Geotechnical Seminar Conference, ASCE, Denver, CO.

Anderson, S. A. and Rivers, B. S. (2013) "Capturing the Impacts of Geotechnical Features on Transportation System Performance". Geo-Congress 2013, ASCE, San Diego, Ca.

Bernhardt, K. L. S., Loehr, J. E., and Huaco, D. (2003) "Asset Management Framework for Geotechnical Infrastructure”. Journal of Infrastructure Systems, 9, 107-116.

Besl, P. J., and McKay, N. D. (1992). “A Method for Registration of 3-D Shapes”. IEEE Transactions on Pattern Analysis and Machine Intelligence, 14(2), 239-256.

Central Federal Lands Highway Division (CFLHD). (2010). "Retaining Wall Inventory and Condition Assessment Program (WIP)" National Park Service Procedures Manual, Lakewood, CO. 
Cloud Compare. (2014). "Cloud to Cloud Compare Workflow". $<$ http://www.danielgm.net $>$ (Sep. 2, 2014).

DeMarco, M. J., Anderson, S. A., and Armstrong, A. (2009). "Retaining Walls Are Assets Too!" Public Roads, 73(1), 30-37.

Douadi, L., Aldon, M. J., and Crosnier, A. (2006). "Pair-wise Registration of 3D/Color Data Sets with ICP”. Proc., Int. Conf. on Intelligent Robots and Systems, IEEE/RSJ, Beijing, China.

Girardeau-Montaut, D., Roux, M., Marc, R., and Thibault, G. (2005). "Change Detection on Point Cloud Data with a Ground Laser Scanner”. ISPRS Workshop Laser Scanning, Enschede, the Neatherlands.

Google Earth. (2014). <http://www.googleearth.com> (Jun. 19, 2014).

Jansson, P. O. (2013). "Preliminary Findings of Retaining Wall Investigation, W2 of 82-22-12 Northbound M-10 North of Schaefer Highway, City of Detroit”. Michigan Department of Transportation (MDOT), Southfield, MI.

Jauregui, D. V., White, K. R., Woodward, C. B., and Leitch, K.R. (2003) “Noncontact Photogrammetric Measurements of Vertical Bridge Deflection”. Journal of Bridge Engineering, 8(4), 212-222.

Jiang, R., Jauregui, D.V., and White, K. R. (2008). "Close-Range Photogrammetry Applications in Bridge Measurement: Literature Review”. Measurement, 41(8), 823834.

Low, K. L. (2004). "Linear Least-Squares Optimization for Point-to-Plane ICP Surface Registration". Technical Report TR04-004, Department of Computer Science, University of North Carolina at Chapel Hill, Chapel Hill, NC. 
Minnesota Department of Transportation (MnDOT). (2013). “Asset Management for Retaining Walls”. Office of Policy Analysis, Research \& Innovation, MN.

Michigan Department of Transportation (MDOT). (2014). "Detroit Maps." $<$ http://www.michigan.gov> (Oct. 10, 2014).

Matthews, N. A. (2008). "Aerial and Close-Range Photogrammetric Technology: Providing Resource Documentation, Interpretation, and Preservation". Technical Note 428. U.S. Department of the Interior, Bureau of Land Management, National Operations Center, Denver, CO.

MathWorks. (2014). "MATLAB The Language of Technical Computing". $<$ http://www.mahworks.com> (Oct. 10, 2014).

Oommen, T., Brooks, C., Cunningham, K., Lautala, P., and Vitton, S. (2013). "Sustainable Geotechnical Asset Management along the Transportation Infrastructure Environment Using Remote Sensing”. Michigan Technological University, Houghton, MI.

Reid, R. L. (2008). “The Infrastructure Crisis: Special Report”. Civil Engineering Magazine, 78(1), 40-65.

Remondino, F., and El-Hakim, S. (2006). "Image-based 3D modelling: a review". The Photogrammetric Record, 21, 269-291.

Schaefer, V., Nichols, S., and Anderson, S. (2013). "Understanding Performance of Foundations, Walls and other Geotechnical Features". Southeastern Geotechnical Engineering Conference, FHWA, Baton Rouge, LA. 
Singh, P. S., Jain, D., and Mandla, V. R. (2014). "Image Based 3D City Modeling: Comparative Study". The International Archives of the Photogrammetry, Remote Sensing and Spatial Information Sciences, XL(5), 537-546.

Stanley, D. (2011). "Asset Management in a World of Dirt” TR News, 277, 18-22.

Veress, S. A., Flint, E. E., Sun, L. L., Hatzopoulos, J., and Jinina, C. (1977). "Photogrammetric Monitoring of a Gabion Wall". Department of Transportation Report No. 31.1, Olympia, WA.

Wendland, S. (2011). "When Retaining Walls Fail". Civil Engineering News, $<$ http://www.cenews.com> (Aug.5, 2014).

Westoby, M.J., Brasington, J., Glasser, N.F., Hambrey, M.J., and Reynolds, J.M. (2012). “'Structure-for-Motion' photogrammetry: A low-cost, effective tool for geoscience applications". Geomorphology, 179, 300-314.

Wohler, C. (2009). "3D Compute Vision: Efficient Methods and Applications". Geometric Approaches to Three-dimensional Scene Reconstruction, Springer, NY.

Wolf, P. R. and Dewitt, B. A. (2000). "Elements of Photogrammetry: with Applications in GIS”. $3^{\text {rd }}$ Ed., McGraw-Hill Co. Inc., NY. 
APPENDIX A: Plots of the laboratory small scale model point cloud accuracy

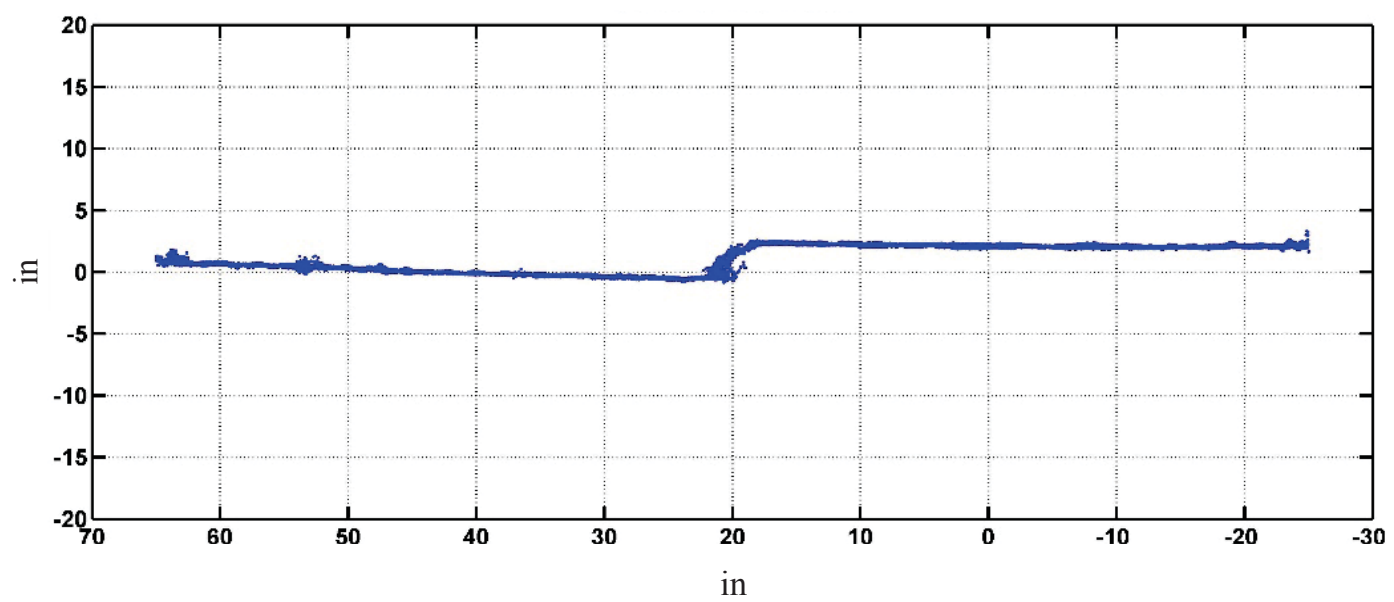

Figure A-1 Plan view of the 3D point cloud of the small scale model with $3.25 \mathrm{in}$ deflection at $20 \mathrm{ft}$ with $35 \mathrm{~mm}$ lens.

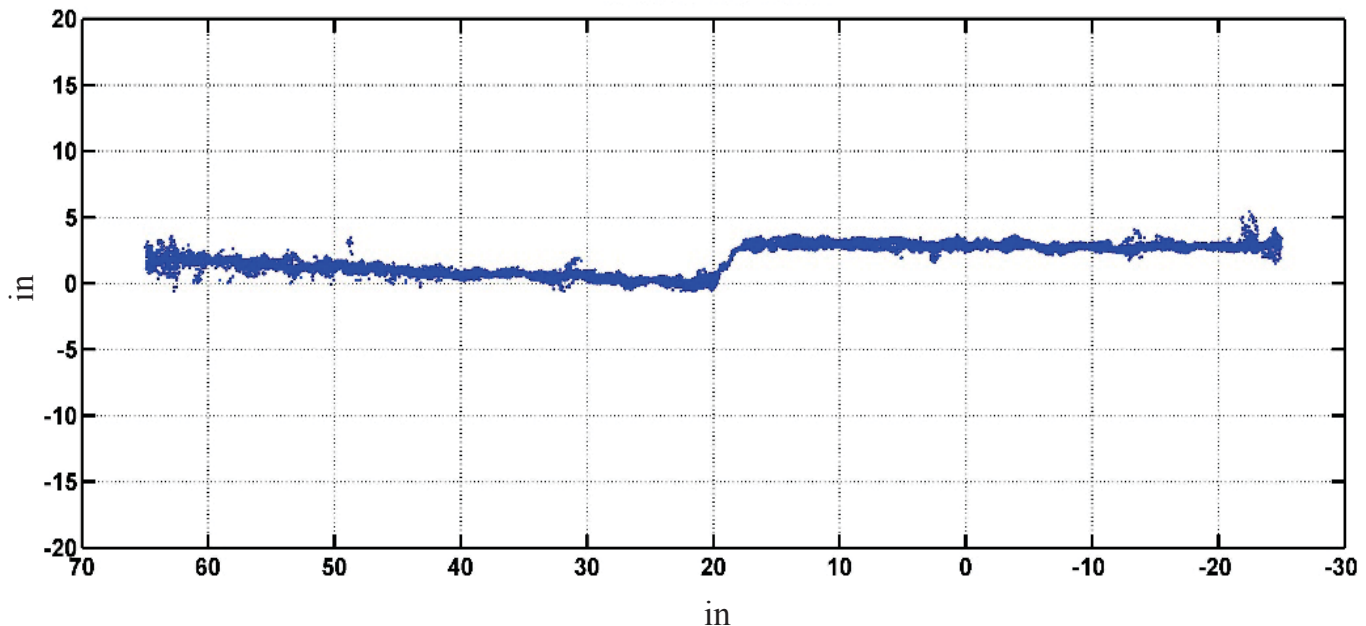

Figure A-2 Plan view of the 3D point cloud of the small scale model with 3.25 in deflection at $40 \mathrm{ft}$ with $35 \mathrm{~mm}$ lens. 


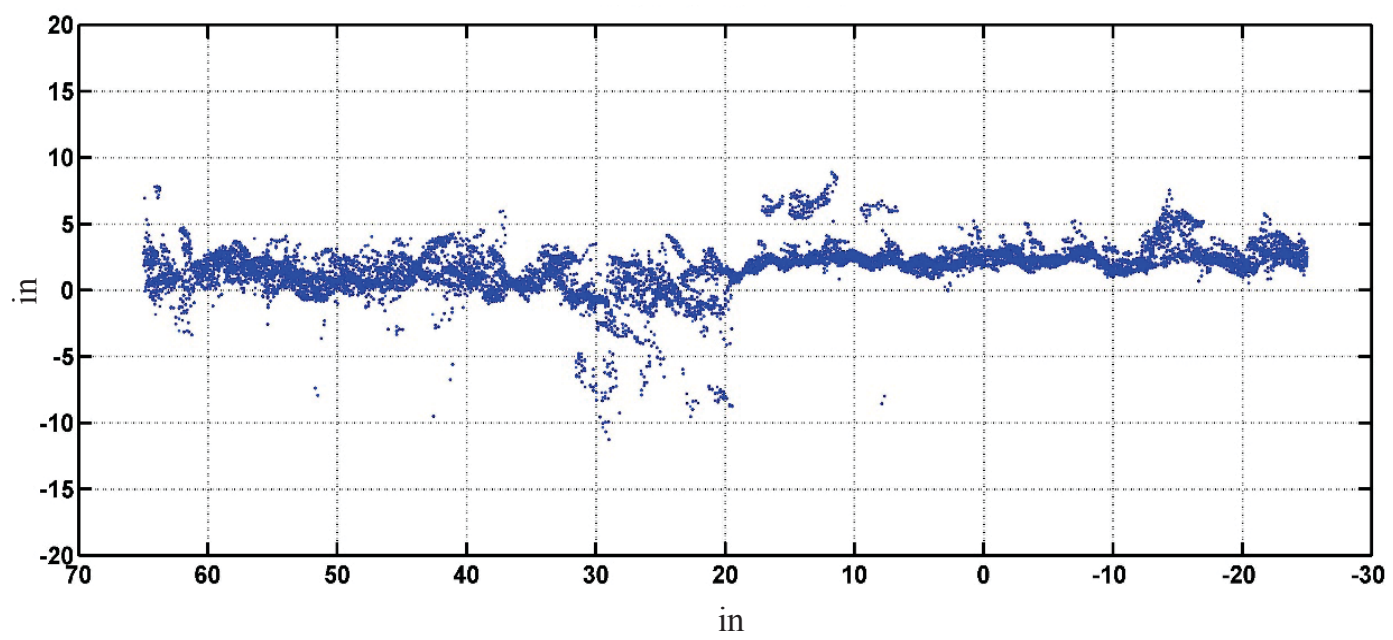

Figure A-3 Plan view of the 3D point cloud of the small scale model with 3.25 in deflection at $50 \mathrm{ft}$ with $55 \mathrm{~mm}$ lens.

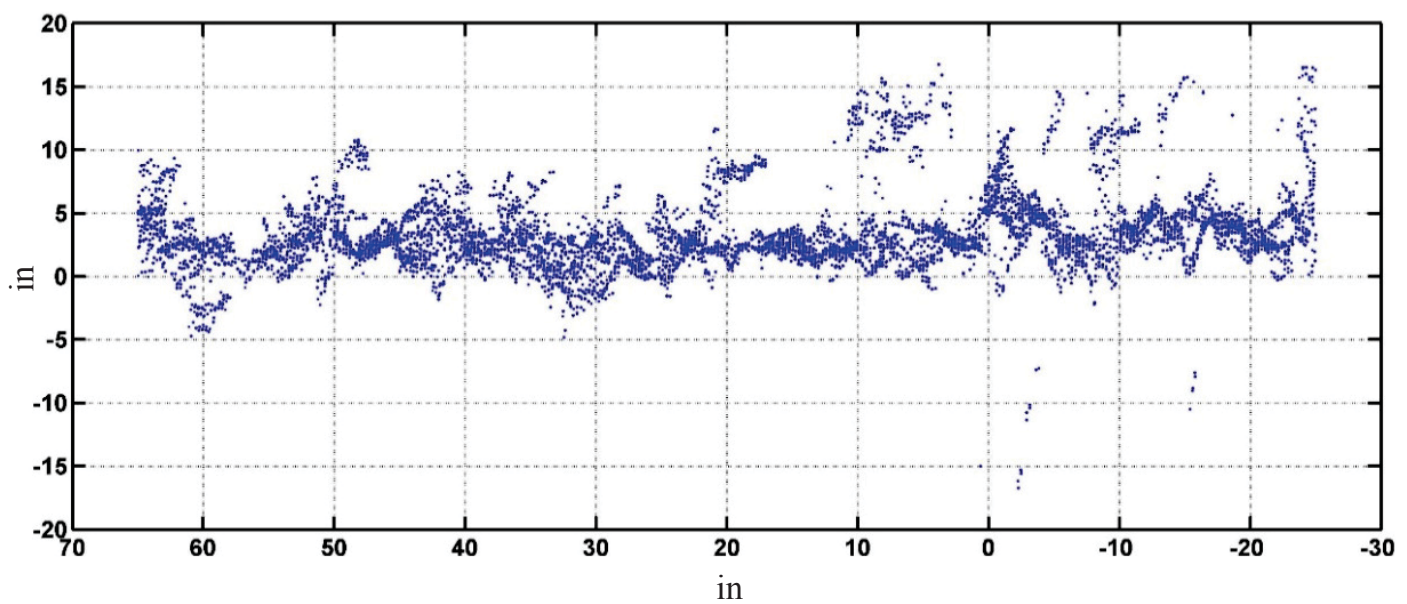

Figure A-4 Plan view of the 3D point cloud of the small scale model with $3.25 \mathrm{in}$ deflection at $60 \mathrm{ft}$ with $55 \mathrm{~mm}$ lens. 


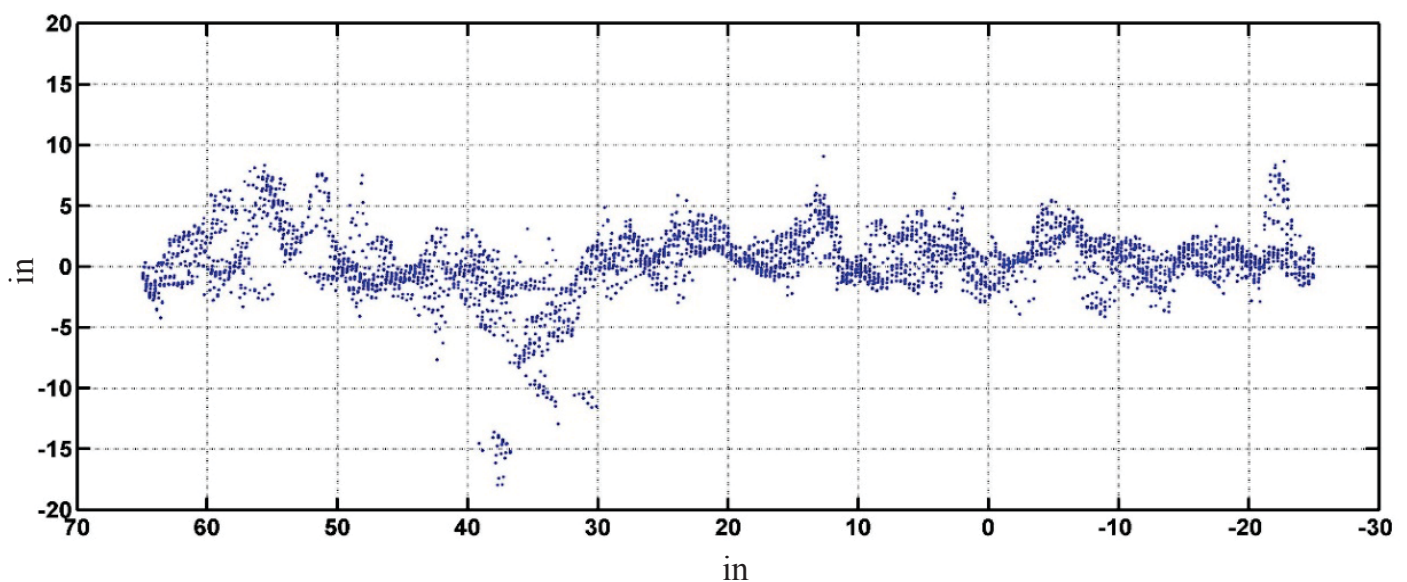

Figure A-5 Plan view of the 3D point cloud of the small scale model with $3.25 \mathrm{in}$ deflection at $80 \mathrm{ft}$ with $55 \mathrm{~mm}$ lens.

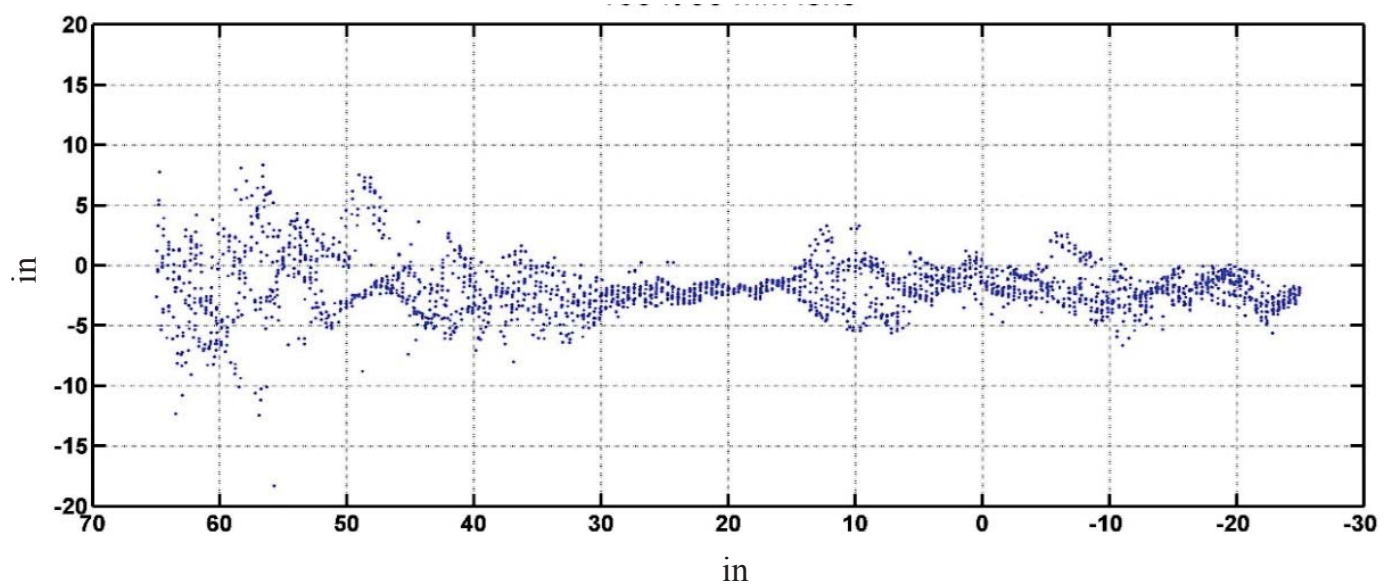

Figure A-6 Plan view of the 3D point cloud of the small scale model with 3.25 in deflection at $100 \mathrm{ft}$ with $55 \mathrm{~mm}$ lens. 


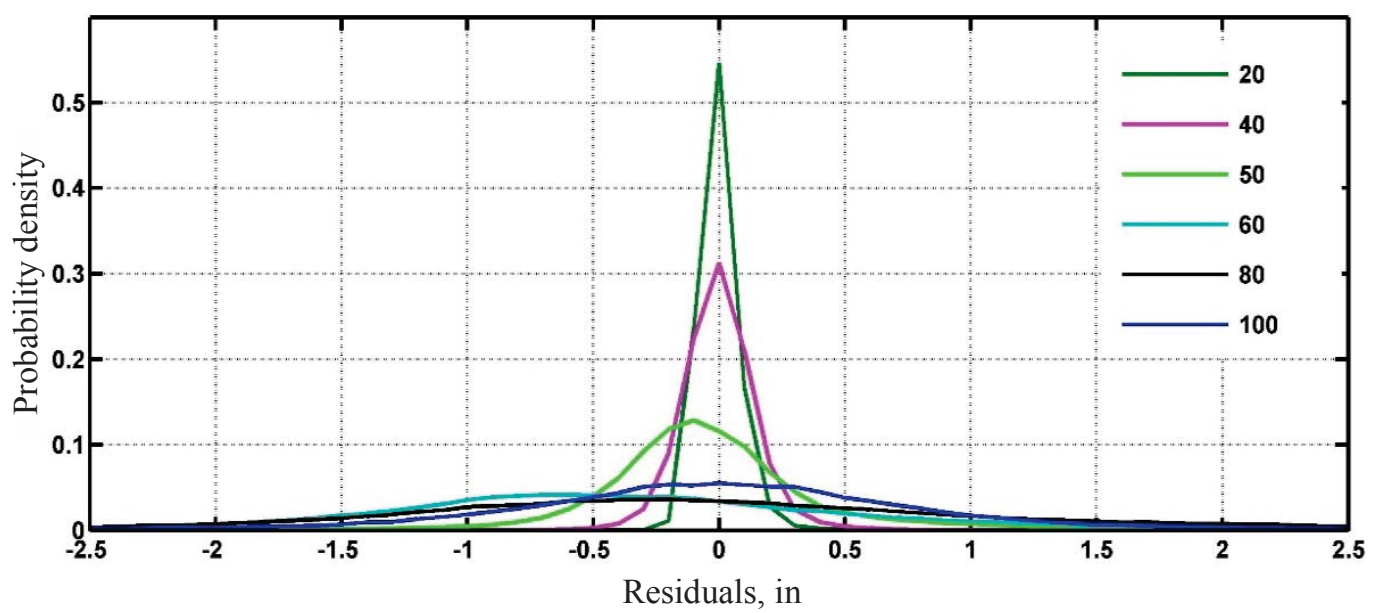

Figure A-7 Probability density distribution curves of the residuals from the planes fit though the 3D point clouds at various distances 


\section{APPENDIX B: Value Differences from change detection from March and June}

\section{datasets for Joint 4 and Joint 3}

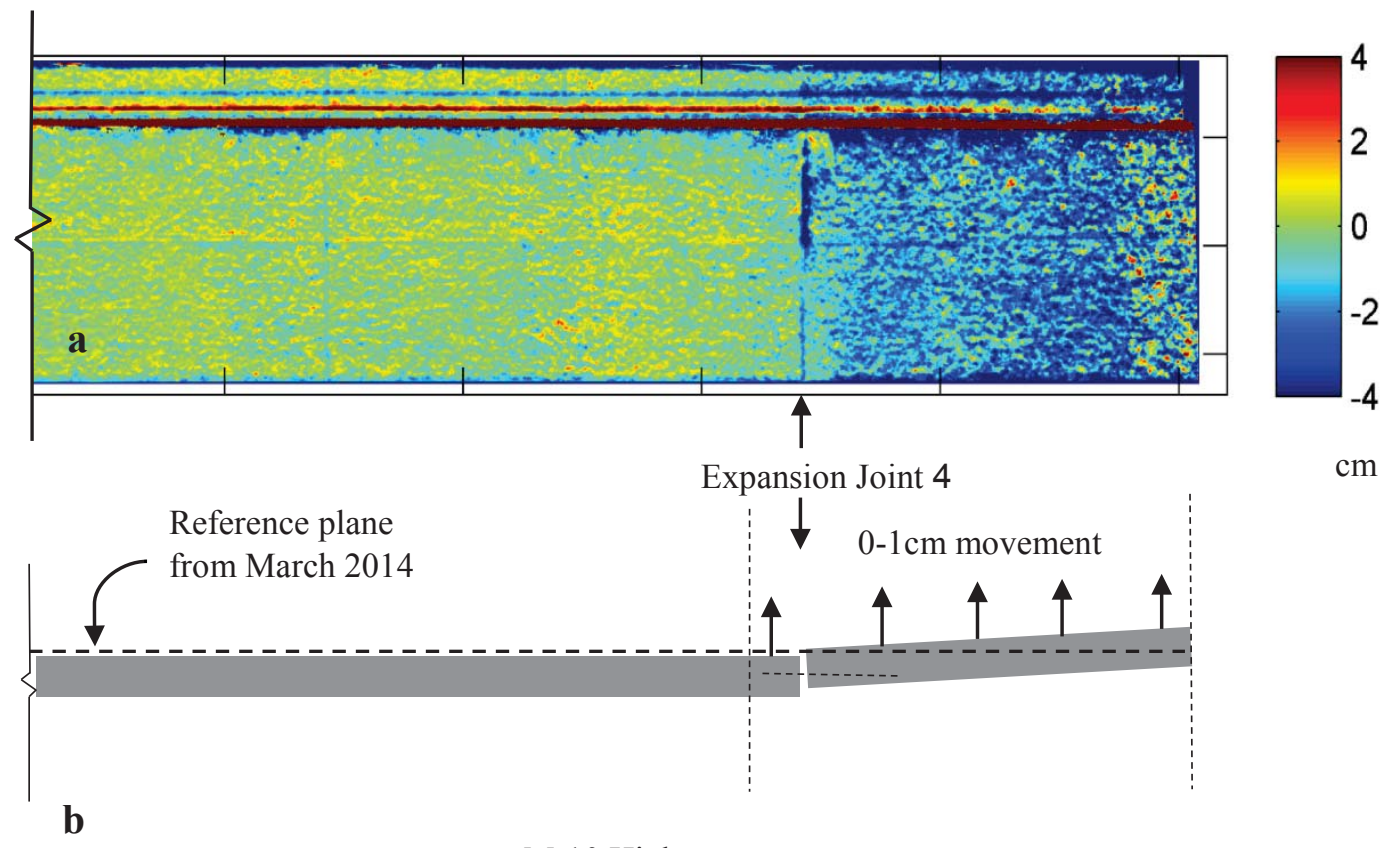

M-10 Highway

Figure B-1 (a) Value differences between March and June for the area around Joint 4. (b) Plan view of the retaining wall sections on both sides of Joint 4 showing the potential horizontal movement towards the highway. 


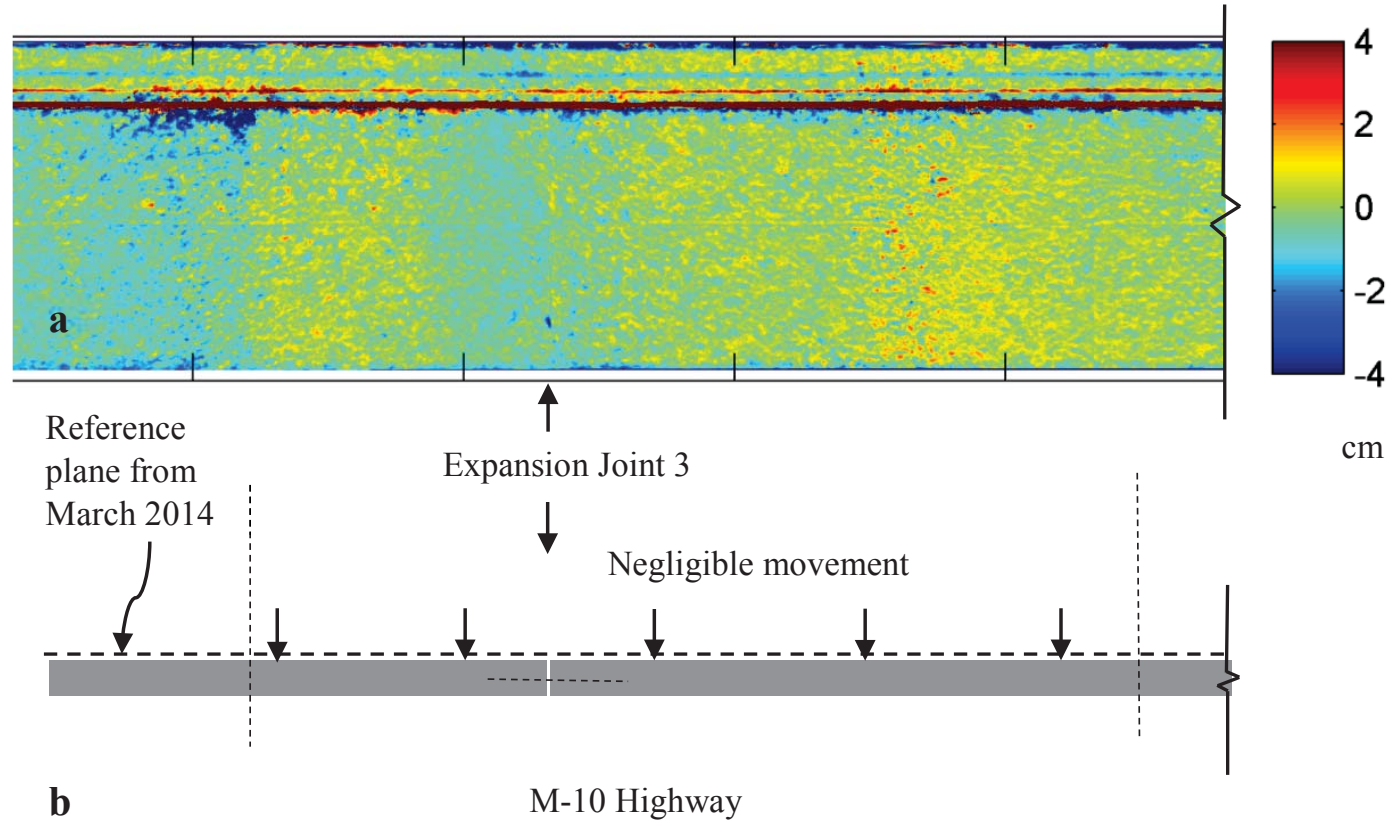

Figure B-2 (a) Value differences between March and June for the area around Joint 3. (b) Plan view of the retaining wall sections on both sides of Joint 3 showing the potential horizontal movement towards the highway. 